\title{
A synaptic mechanism for network synchrony
}

\section{Simon T. Alford * and Michael H. Alpert}

Department of Biological Sciences, University of Illinois at Chicago, Chicago, IL, USA

\section{Edited by:}

Sergey M. Korogod, National

Academy of Sciences of Ukraine,

Ukraine

Reviewed by:

Patrik Krieger, Ruhr University

Bochum, Germany

Stefano Taverna, Italian Institute of

Technology, Italy

\section{${ }^{*}$ Correspondence:}

Simon T. Alford, Department of Biological Sciences, University of Illinois at Chicago, M/C 068, Rm 4285, 840 West Taylor Street, Chicago, IL 60607, USA

e-mail: sta@uic.edu
Within neural networks, synchronization of activity is dependent upon the synaptic connectivity of embedded microcircuits and the intrinsic membrane properties of their constituent neurons. Synaptic integration, dendritic $\mathrm{Ca}^{2+}$ signaling, and non-linear interactions are crucial cellular attributes that dictate single neuron computation, but their roles promoting synchrony and the generation of network oscillations are not well understood, especially within the context of a defined behavior. In this regard, the lamprey spinal central pattern generator (CPG) stands out as a well-characterized, conserved vertebrate model of a neural network (Smith et al., 2013a), which produces synchronized oscillations in which neural elements from the systems to cellular level that control rhythmic locomotion have been determined. We review the current evidence for the synaptic basis of oscillation generation with a particular emphasis on the linkage between synaptic communication and its cellular coupling to membrane processes that control oscillatory behavior of neurons within the locomotor network. We seek to relate dendritic function found in many vertebrate systems to the accessible lamprey central nervous system in which the relationship between neural network activity and behavior is well understood. This enables us to address how $\mathrm{Ca}^{2+}$ signaling in spinal neuron dendrites orchestrate oscillations that drive network behavior.

Keywords: lamprey, oscillation, $\mathrm{SK} 2, \mathrm{~K}_{\mathrm{Ca}} 2$, NMDA, locomotion, calcium, dendrites

\section{INTRODUCTION}

Orchestration of neuronal activity within networks is integral to correct execution of behavior. Synchronization between groups of neurons is an organizational feature of many neural networks found in the central nervous systems of invertebrates (Wehr and Laurent, 1996; Riffell et al., 2009) to vertebrates (Womelsdorf et al., 2014) alike, and between microcircuits. Largescale synchrony between neurons is particularly evident in the spinal (Grillner, 2003; Goulding, 2009) and brainstem networks (Koshiya and Smith, 1999) controlling rhythmic movement, but are also common to hippocampal and neocortical networks (Buzsáki and Draguhn, 2004; Grillner et al., 2005; Yuste et al., 2005). Synchronously active microcircuits, like the neurons that comprise the lamprey spinal central pattern generator (CPG), are driven through the synaptic connectivity of excitatory and inhibitory neurons combined with intrinsic burst-terminating electrical properties (Wallén and Grillner, 1987; Buchanan, 1993). However, little is known about the electrical and integrative properties of the complex dendritic architecture of lamprey spinal neurons where synaptic- and voltage-dependent conductances shape potentials arriving at the soma. In contrast, the integrative properties of cortical pyramidal neuron dendrites and their synaptic inputs have been extensively characterized (Spruston, 2008), while less is known about how these intrinsic properties generate rhythmic network activity, and ultimately the behaviors they are thought to subserve. To understand how neural networks generate complex patterns of activity underlying behaviors, it will be necessary to understand both the specific patterns of connectivity between neurons and how individual neurons respond to the inputs that they receive. Thus, this review seeks to merge disparate fields of research-dendritic integration and spinal central pattern generation. In doing so, we hypothesize that the ionic mechanisms driven through two rhythm-generating conductances, namely the synaptic interaction between ensembles of NMDA receptors (NMDARs) and $\mathrm{Ca}^{2+}$-dependent $\mathrm{K}^{+}$ channels, may have general implications for the synchronization of spinal to cortical networks. Thus, to explore the idea that active dendritic properties are at the core of this behavior, we examine in detail the lamprey spinal network and draw from other areas of dendritic research to enhance our understanding of what occurs at the level of the dendritic synapse to generate behavior.

\section{SUPRASPINAL NETWORKS IN THE BRAINSTEM INITIATE AND MAINTAIN LOCOMOTOR DRIVE}

Vertebrate locomotion is initiated and maintained by evolutionarily conserved serial pathways originating in the forebrain (Ericsson et al., 2013; Grillner et al., 2013), projecting to the mesencephalic locomotor region (MLR; Dubuc et al., 2008) and then to command neurons of the reticulospinal (RS) system, which innervates the entire rostro-caudal extent of the spinal cord, including cervical and lumbar centers in mammals (Goulding, 2009), and all segmental levels in fish as well as lamprey (Buchanan et al., 1987). However, following their 
activation by the brainstem, it is the circuits and neurons of the spinal CPG (Buchanan and Cohen, 1982) that create the complex synergy that rhythmically activates the locomotor musculature (Grillner et al., 2008). The structure of descending commands to spinal CPGs and the synaptic connectivity of the spinal network itself provides an opportunity to understand how dendritic activation within behaviorally relevant circuits underlies the astonishing complexity of vertebrate behavioral patterns. The circuitry of the lamprey CPG is well understood (Grillner et al., 2000, 2008) including the identities of the key neurons (Rovainen, 1974; Buchanan and Cohen, 1982), their neuronal targets, and neuropharmacology (Alford et al., 2003). However, in common with most neurons, these circuit components possess a complex dendritic morphology (Figure 1), yet we understand little of the spatiotemporal profile of dendritic activation within these neurons and the role that such patterns of activation might play in the physiological activity of the neurons during behavior. This lack of understanding is true for simple inputs, but particularly during goal-directed locomotion. This is partly because tracing the spatial distribution of physiological targets of neurons is challenging, but also because most studies of CPGs, whether in simple systems like the lamprey, or in more complex systems such as mammals, use isolated spinal cords and activate the networks pharmacologically (Sigvardt et al., 1985; Rossignol et al., 1998; Kyriakatos et al., 2011). This undoubtedly obscures the precise physiologically relevant spatiotemporal activation patterns of dendritic synapses that would otherwise drive these behaviors in vivo. In studies of spinal motor activity this has been largely overlooked perhaps due to the strong resemblance of electrophysiological output (i.e., fictive locomotion), or even actual movement, to observed locomoting animals. Despite this similarity, it is crucial to understand how physiological patterns of synaptic input and intrinsic membrane electrodynamics generate rhythmic behaviors.

\section{THE SYNAPTIC CONNECTIVITY OF THE SPINAL CPG NETWORK DRIVES RHYTHMIC NETWORK OSCILLATIONS}

The very fluid, controlled nature of lamprey locomotion is produced after RS axons activate the local circuit neurons within the spinal ventral horn (Figure 2). Among these neurons, collectively referred to as ventral horn neurons (VHNs), the best characterized neurons responsible for pattern generation are excitatory interneurons (EINs) that provide ipsilateral, glutamatergic excitation (Buchanan and Grillner, 1987; Buchanan et al., 1989), while crossed caudally projecting interneurons (CCINs) provide contralateral, glycinergic inhibition (Grillner and Wallén, 1980; Alford and Williams, 1989). Motor neurons are the final common output neuron of each segment, which bundle into ventral roots (VRs) as they leave the spinal cord, before synapsing directly onto myotomal cells of the trunk musculature (Buchanan and Cohen, 1982). The precise, synaptic connectivity of the VHNs within and between individual segments serves to ipsilaterally excite (i.e., EINs), while simultaneously delivering contralateral inhibition (i.e., CCINs; Buchanan and Grillner, 1987). This reciprocally inhibited network ensures that within each segment, when one side of the trunk musculature contracts, the contralateral

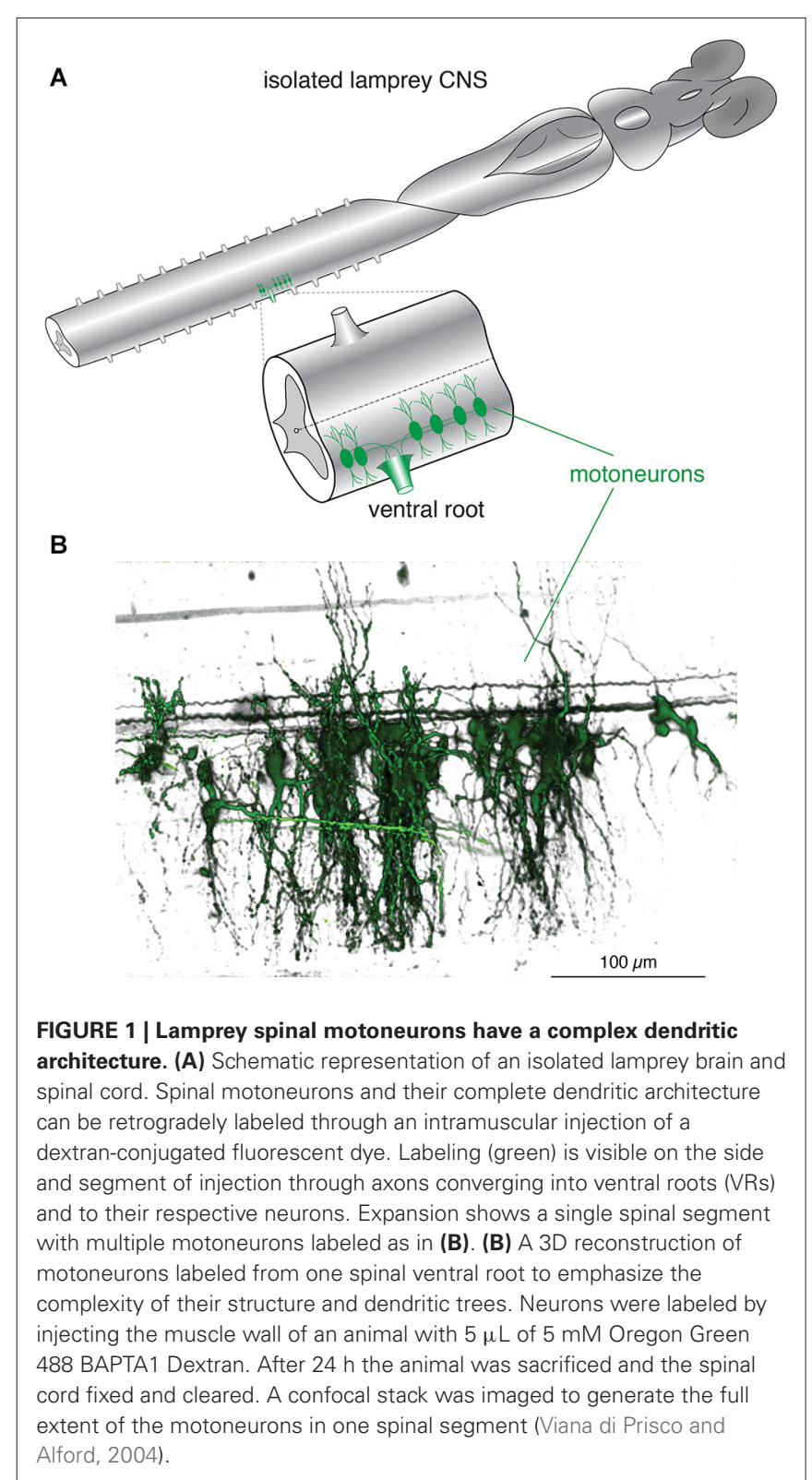

side is inhibited. Lateral interneurons, which project ipsilaterally to inhibit CCINs, facilitate the relief of reciprocal inhibition (Buchanan, 1982). However, the importance of lateral interneurons in maintaining network rhythmicity has been less emphasized because alternating, rhythmic bursting can persist in their absence as demonstrated by computer simulation (Wallén et al., 1992).

Work in lamprey (Grillner et al., 1981; Brodin et al., 1985, 1988; Brodin and Grillner, 1985; Buchanan and Grillner, 1987), Xenopus tadpoles (Dale and Roberts, 1984; Roberts and Alford, 1986), rats (Kudo and Yamada, 1987), and cats (Douglas et al., 1993) demonstrates that spinal glutamate receptor-mediated transmission activates and maintains locomotion. These data are supported by recordings of excitatory postsynaptic potentials (EPSPs) onto motoneurons and premotor interneurons 


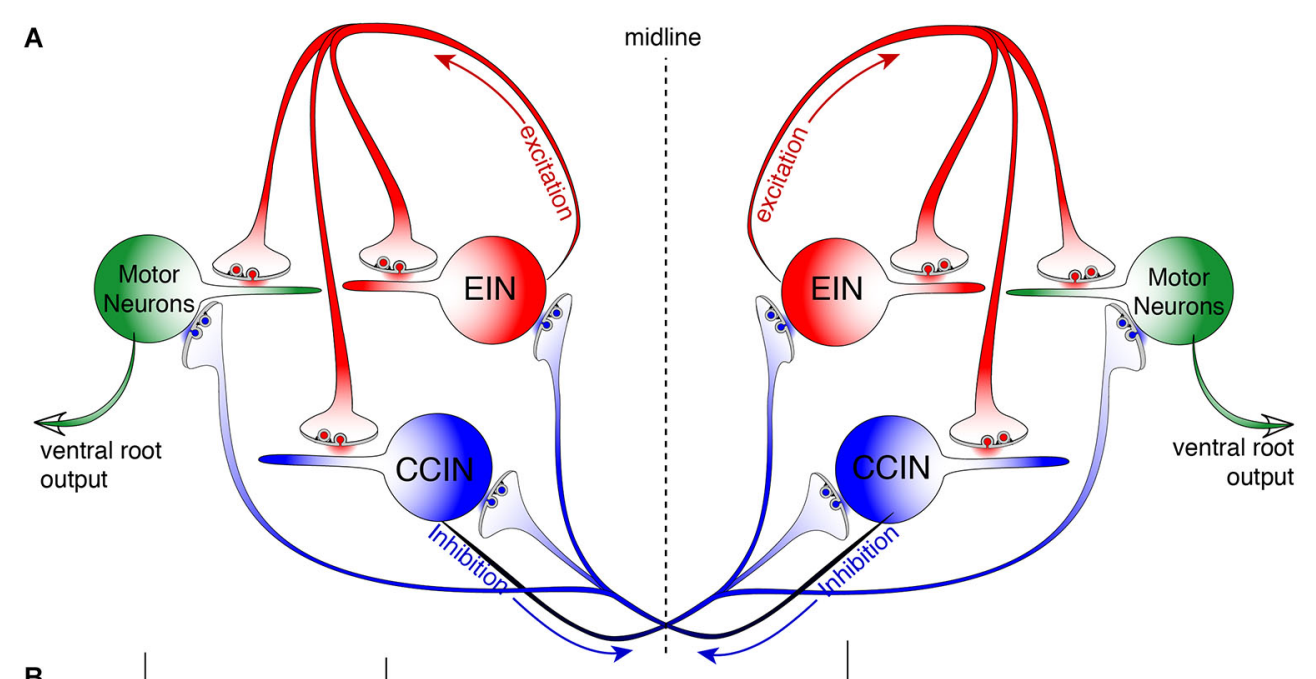

B

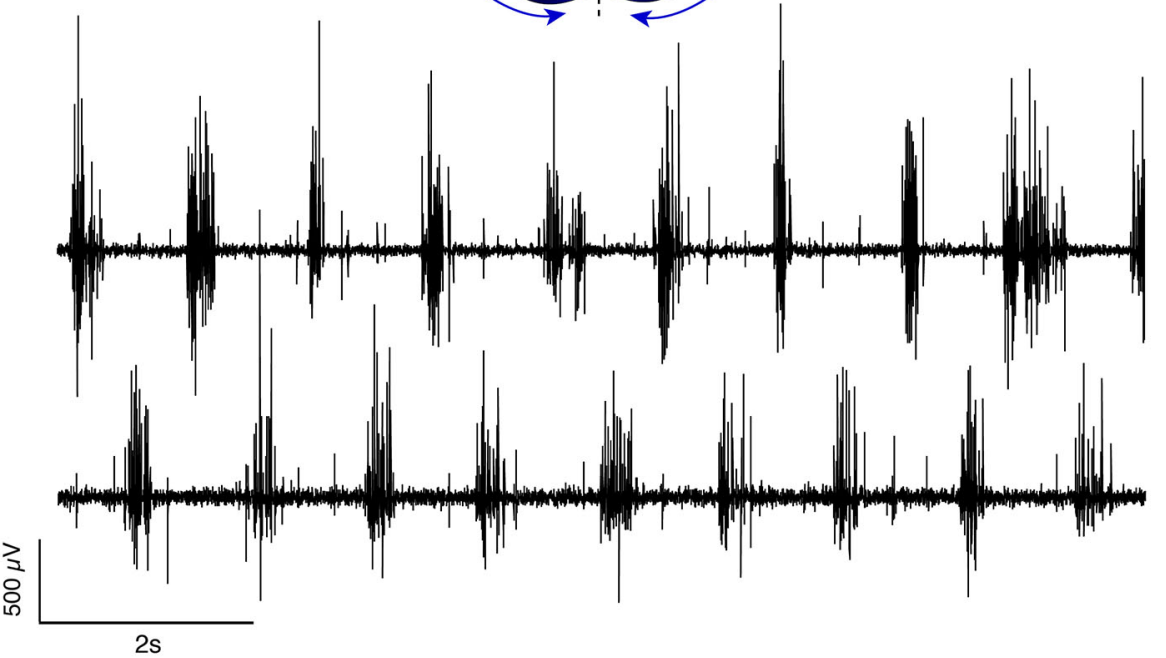

FIGURE 2 | Schematic representation of the lamprey spinal central pattern generator. (A) Spinal CPG neurons receive both ipsilateral glutamatergic (red) input from excitatory interneurons (EINs, red) and contralaterally projecting glycinergic inhibition (blue) from reciprocally inhibiting, crossed glycinergic interneurons (CCINs, blue). Output of the CPG occurs from motoneurons (green), which directly synapse onto myotomal cells of the trunk musculature to cause muscle contraction producing rhythmic locomotion. (B) Output pattern recorded using glass suction electrodes from paired, contralateral (top vs. bottom traces) VRs showing alternating bursting of the spinal network during rhythmic locomotion. The reciprocally connected network described in (A) prevents excitation of the contralateral spinal cord when the ipsilateral side is bursting for each cycle (burst-to-burst), leading each side of the spinal cord to be precisely $180^{\circ}$ out-of-phase from the other (Alford et al., 2003).
(Dale and Roberts, 1985; Brodin et al., 1988; Noga et al., 2003) and pharmacological manipulation of the resultant behaviors (Brodin and Grillner, 1985; Dale and Roberts, 1985; Cazalets et al., 1992; Chau et al., 2002; Rybak et al., 2006). This neurotransmission both directly excites neurons of the $\mathrm{CPG}$, and also activates complex non-linear membrane interactions, or oscillations, in these neurons mediated by NMDAR voltage-dependency and $\mathrm{Ca}^{2+}$ permeability coupled to the activation of $\mathrm{Ca}^{2+}$-dependent currents. The cellular processes underlying such oscillations are believed to be central to the coordination of locomotor behavior. In lampreys the identity of the descending glutamatergic RS command neurons is well-defined (Dubuc et al., 2008) and similarly spinal neurons that release glutamate locally within the spinal ventral horn (i.e., EINs) have been identified (Buchanan et al., 1989;
Buchanan, 1993) as has their network role (Wallén et al., 1992).

One prominent feature of the spinal network is that it transforms unpatterned, exogenous glutamatergic input into a patterned, rhythmic output. The details of synaptic connectivity responsible for this phenomenon have been substantially explored in the lamprey (Wallén and Grillner, 1987; Grillner et al., 2001; Grillner, 2006) and the Xenopus embryo (Dale and Roberts, 1984, 1985). More recently, work in higher vertebrates (Masino et al., 2012) has emphasized how well conserved this network motif is throughout the vertebrate subphylum including lampreys, fishes, amphibians, chelonids and mammals (Dale and Roberts, 1984; Sigvardt et al., 1985; Kudo and Yamada, 1987; Hernandez et al., 1991; Guertin and Hounsgaard, 1998; Gabriel et al., 2009; Masino et al., 2012). After complete 
spinal transection (Cohen and Wallén, 1980; Brodin et al., 1985), the lamprey swimming network can still generate the electrophysiological correlates of swimming. While recording output from pairs of contralateral VRs using glass suction electrodes, excitatory amino acid (EAA) receptor agonists, such as kainate, $D$-glutamate, or $N$-methyl- $D$-aspartic acid (NMDA; Brodin et al., 1985; Brodin and Grillner, 1985; Wallén and Grillner, 1987), bath-applied to an isolated spinal cord (devoid of muscle or any other surrounding tissue) generates antiphasic bursts of activity across the spinal midline-the phase relationship across sides of the spinal cord is enforced by glycinergic inhibition (Cohen and Wallén, 1980; Alford and Williams, 1989)—and the same rostro-caudal phase lag as seen in intact behavior (Wallén and Williams, 1984). This network behavior, termed "fictive locomotion", refers to the electrical output of the spinal CPG. Thus, the network acts as a CPG, a term that refers collectively to centrally located, local circuit spinal neurons that provide precise rhythmic output from spinal motoneurons. The spinal CPG operates in the absence of both sensory feedback from the spinal dorsal roots or descending networks and is found in all vertebrates (Kahn and Roberts, 1978; Forssberg et al., 1980; Roberts et al., 1981; Sholomenko and Steeves, 1987; Delvolvé et al., 1997; Field and Stein, 1997; Masino and Fetcho, 2005). Thus, the ability to generate rhythmic output via network oscillations is inherent to the spinal network itself and does not require supraspinal control.

\section{SINGLE NEURONS ARE INTRINSICALLY RHYTHMIC}

The study of spinal neurons offers a unique insight into how properties of neural networks emerge from membrane activity at the cellular level and provides a straightforward behavioral contextlocomotion-in which to place this activity. EAA agonists, like NMDA, cause the membrane potential $\left(V_{m}\right)$ of individual VHNs in isolated spinal cords to undergo repetitive oscillations that are in-phase with the ipsilateral VR of the corresponding hemisegment (Sigvardt et al., 1985; Wallén and Grillner, 1987). During the depolarized phase, the cells can fire multiple action potentials (APs) before the cell is repolarized. This finding demonstrates how electrical properties of single cells within a network scale to direct the behavior of the network at large. Most VHNs oscillate in NMDA driven by phase-appropriate synaptic excitation from EINs and subsequent hyperpolarization from CCINs (Buchanan and Cohen, 1982). However, when tetrodotoxin (TTX) is applied, spiking is abolished, while the underlying $V_{m}$ oscillation persists (Wallén and Grillner, 1987). Since TTX pharmacologically isolates the recorded neuron by preventing synaptic communication within the network, the cell then oscillates with tonic exposure to NMDA. This phenomenon, termed NMDA-dependent, TTXresistant oscillations (NMDA-TTX oscillations), is seen in most lamprey VHNs. This demonstrates that spinal neurons show intrinsic membrane properties that are capable of hyperpolarizing the cell during constant depolarizing challenge from an agonist. The net effect is to produce $V_{m}$ oscillations. Removal of $\mathrm{Mg}^{2+}$ from the perfusing Ringer's solution abolishes the oscillation and causes the neurons to remain at depolarized potentials because $\mathrm{Mg}^{2+}$ confers voltage-sensitivity to the NMDAR (Wallén and Grillner, 1987). Thus, the intrinsic membrane property of spinal neurons that causes oscillations is subject to the voltagedependency of $\mathrm{Mg}^{2+}$ block of the NMDAR.

More generally within the nervous system, NMDARs have been well characterized as non-specific cation channels permeable to $\mathrm{Na}^{+}, \mathrm{K}^{+}$, and $\mathrm{Ca}^{2+}$ (MacDermott et al., 1986; Ascher and Nowak, 1988). More recently, NMDAR-dependent $\mathrm{Ca}^{2+}$ entry has been demonstrated to be integral to dendritic computation (Branco et al., 2010) through regenerative "NMDA spikes" in pyramidal neurons (Schiller and Schiller, 2001; Larkum et al., 2009) with roles spanning from the induction of synaptic plasticity (Alford et al., 1993) to behavior (Smith et al., 2013b). In lamprey VHNs, removal of $\mathrm{Ca}^{2+}$ from the ringer and replacement with $\mathrm{Ba}^{2+}$ (an equivalent divalent cation which can also permeate $\mathrm{Ca}^{2+}$ ionophores) during NMDA-TTX oscillations causes the cell to become similarly trapped at a depolarized $V_{m}$. Thus, $\mathrm{Ca}^{2+}$ is necessary to hyperpolarize the cell from the depolarized state. $\mathrm{Ca}^{2+}$ activates myriad $\mathrm{Ca}^{2+}$-dependent proteins. In particular, VHNs contain $\mathrm{Ca}^{2+}$-dependent $\mathrm{K}^{+}$channels (El Manira et al., 1994; Wall and Dale, 1995; Han et al., 2007; Li and Bennett, 2007), which upon binding $\mathrm{Ca}^{2+}$, rapidly open a $\mathrm{K}^{+}$channel that hyperpolarizes the cell. This "excitation-inhibition coupling" is a mechanism that effectively allows the cell to "turn off" autonomously following activation.

The $\mathrm{Ca}^{2+}$-dependent $\mathrm{K}^{+}$channel of the $\mathrm{K}_{\mathrm{Ca}} 2$ subtype (formerly SK2 (Wei et al., 2005)) participates in two distinct processes in lamprey VHNs both of which are integral to the behavioral locomotor output of the spinal cord. Its most well-described role follows the AP when depolarization activates $\mathrm{N}$ - and P/Qtype (Wikström and El Manira, 1998) voltage-gated $\mathrm{Ca}^{2+}$ channels (VGCCs) and the entering $\mathrm{Ca}^{2+}$ activates $\mathrm{K}_{\mathrm{Ca}} 2$ channels to cause an afterhyperpolarization (AHP; Figure 3; Hill et al., 1992; Meer and Buchanan, 1992). The AHP can be divided into fast, medium and slow subcomponents, of which the medium AHP (mAHP) is mediated by $\mathrm{K}_{\mathrm{Ca}} 2$ channels (Bond et al., 2004). Due to slow kinetics (decay time constant of $\sim 200 \mathrm{~ms}$ ), the mAHP mediates spike frequency adaptation, the reduction in spike frequency from repeated spiking, by raising the relative threshold for subsequent AP generation due to an increase in $\mathrm{K}^{+}$conductance. Blockade of $\mathrm{K}_{\mathrm{Ca}} 2$ channels with the selective antagonist, apamin, increases spike frequency from intracellular current pulses (Meer and Buchanan, 1992; Díaz-Ríos et al., 2007; Jones and Stuart, 2013). $\mathrm{K}_{\mathrm{Ca}} 2$ channels are extremely important for regulating neuronal firing, conserved among different species and cell types (Meer and Buchanan, 1992; Sah and Bekkers, 1996; Marrion and Tavalin, 1998; Wikström and El Manira, 1998; Faber and Sah, 2002; Bloodgood and Sabatini, 2007; Jones and Stuart, 2013).

The second role for $\mathrm{K}_{\mathrm{Ca}} 2$ lies in the plateau termination and membrane repolarization during NMDA-TTX oscillations (Figure 3). The ionic mechanism driving $V_{m}$ oscillations is well-characterized and is hypothesized to proceed as: (1) NMDAR activation depolarizes VHNs; (2) increasing NMDAR conductance by ejecting $\mathrm{Mg}^{2+}$ from the pore; (3) causing further depolarization and $\mathrm{Ca}^{2+}$ entry via the NMDAR as the $V_{m}$ plateaus; (4) which activates $\mathrm{K}_{\mathrm{Ca}} 2$ channels to hyperpolarize the cell; and (5) ending the depolarized plateau to repolarize the cell where it can repeat the cycle (Wallén and Grillner, 


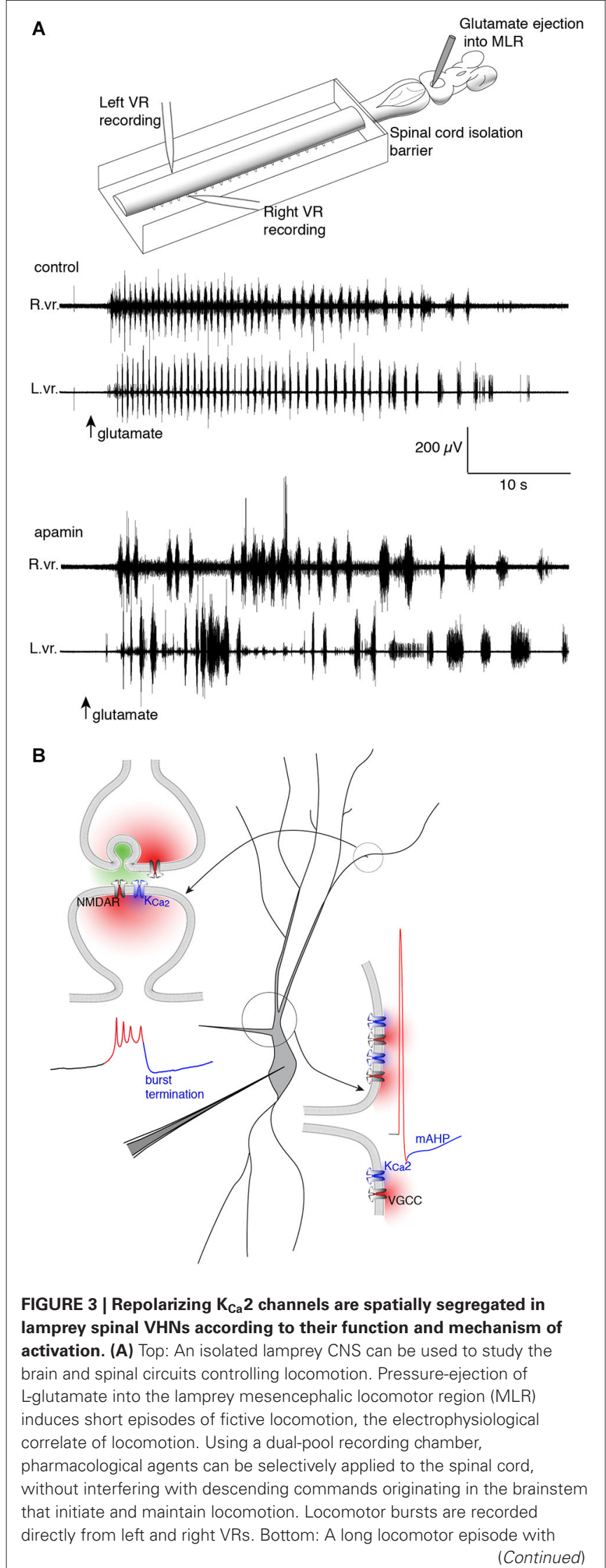

\section{FIGURE 3 | Continued}

regular, alternating bursts (control) follows after a puff of glutamate into the MLR (arrow, glutamate). Blockade of $\mathrm{K}_{\mathrm{Ca}} 2$ channels with the selective antagonist, apamin, decreases the burst frequency and disrupts the alternating locomotor rhythm. This demonstrates the necessity of $\mathrm{K}_{\mathrm{Ca}} 2$ channels for correct alternation and regularity of the locomotor rhythm (Nanou et al., 2013). (B) The effect of $\mathrm{K}_{\mathrm{Ca}} 2$ channel blockade on locomotion can be explained by the role the channel plays at the cellular level. Within $\mathrm{VHNs}, \mathrm{K}_{\mathrm{Ca}} 2$ currents may be evoked either at synapses (top left) whereby synaptic release of glutamate activates NMDAR-mediated $\mathrm{Ca}^{2+}$ entry and thereby closely located $\mathrm{K}_{\mathrm{Ca}_{2}} 2$ channels. It is this $\mathrm{K}_{\mathrm{Ca}} 2$-mediated current that is critical for the termination of NMDA-TTX oscillations (blue portion of trace) shown below recorded from somatic microelectrode recordings. $\mathrm{K}_{\mathrm{Ca}}$ 2-mediated currents are also responsible for the mAHP seen following action potential firing shown at bottom left. However, this current is activated following $\mathrm{Ca}^{2+}$ entry from VGCCs.

1987). Selective blockade of $\mathrm{K}_{\mathrm{Ca}} 2$ channels with apamin (El Manira et al., 1994) or UCL 1684 (Alpert and Alford, 2013) prolongs the oscillation, and can even abolish the oscillation completely. The cell becomes trapped in a depolarized state, similar to extracellular $\mathrm{Ca}^{2+}$ removal, the substitution of $\mathrm{Ca}^{2+}$ for $\mathrm{Ba}^{2+}$, or non-specific blockade of $\mathrm{K}^{+}$channels (Grillner and Wallén, 1985; Grillner et al., 2001). Thus, $\mathrm{K}_{\mathrm{Ca}} 2$ channels are necessary for rhythmogenesis (Figure 3) in lamprey VHNs by supplying a cell-autonomous repolarization, or "off signal", without the need of network inhibition (Nanou et al., 2013).

\section{DENDRITIC $\mathrm{Ca}^{2+}$ SIGNALING IS DYNAMIC AND DETERMINED BY CELLULAR AND MICROCIRCUIT PROPERTIES}

$\mathrm{K}_{\mathrm{Ca}} 2$ channels within a single neuron have more than one distinct computational role. Two have been identified in lamprey VHNs, both subject to intracellular $\mathrm{Ca}^{2+}$ dynamics. Such a functional sub-specialization may be explained both by distinct spatial locations of channel expression and the adequate spatial and functional coupling to distinct sources of $\mathrm{Ca}^{2+}$ contributing to $\mathrm{K}_{\mathrm{Ca}} 2$ activation (Figure 3). Indeed, N- and $\mathrm{P} / \mathrm{Q}$-type (Wikström and El Manira, 1998) VGCCs are activated during the AP in lamprey, triggering $\mathrm{Ca}^{2+}$ entry that activates $\mathrm{K}_{\mathrm{Ca}} 2$ channels underlying the mAHP. However, the mAHP activated by somatic current injection is unaffected by NMDA application (Hill et al., 1989). This distinct separation between mAHP activation and NMDA-TTX oscillation repolarization can be explained by NMDAR-generated $\mathrm{Ca}^{2+}$ entry occurring in spatially distinct cellular sub-regions from VGCC-generated $\mathrm{Ca}^{2+}$ entry during the AP. Across different species and neuron types, the precise subtypes of VGCCs can differ, but to mediate the mAHP, $\mathrm{K}_{\mathrm{Ca}} 2$ channels must be sufficiently close to VGCCs to be activated by their $\mathrm{Ca}^{2+}$ permeation. Similarly, $\mathrm{K}_{\mathrm{Ca}} 2$ channels mediating repolarization during NMDATTX oscillations should be coupled to a distinct $\mathrm{Ca}^{2+}$ source, or a $\mathrm{Ca}^{2+}$ source in a distinct subcellular location. The two likely candidates for the latter are NMDARs and VGCCs (Wallén and Grillner, 1987)-located separately from those responsible for the mAHP (Hill et al., 1989)—while $\mathrm{Ca}^{2+}$ released from internal stores might also contribute. NMDAR activation is necessary to initiate oscillations, but as they lead to membrane depolarization, this may subsequently activate VGCCs. However, release from 
internal stores likely contributes little because their depletion has no effect on NMDA-induced swimming (Krieger et al., 2000)_ a behavior to which NMDAR-dependent intrinsic oscillations contribute. The subcellular location of $\mathrm{K}_{\mathrm{Ca}} 2$ channels responsible for the repolarization may also be critical because physiological NMDAR activation requires the presynaptic release of glutamate, which occurs only at synapses. Determining the route of $\mathrm{Ca}^{2+}$ entry for repolarization of the oscillation is important for understanding how distinct $\mathrm{Ca}^{2+}$ domains and their coupling to $\mathrm{K}_{\mathrm{Ca}} 2$ channels impacts computation both within individual neurons and between synaptically connected neurons.

The spatial and temporal patterning over which dendritic $\mathrm{Ca}^{2+}$ signaling occurs in spinal motor system VHNs during locomotion in lamprey (or in other vertebrate systems) is unknown. Do many dendrites receive synchronous input from their various synaptic partners? Does input occur in discrete spatial locations? The location and timing of synaptic input is crucial for the transmission of potentials arriving at the soma, which will greatly influence neuronal output (Larkum et al., 1999; Stuart and Häusser, 2001; Jarsky et al., 2005). Indeed, dendritic mechanisms that are location-dependent and rely on clustered NMDAR-dependent input generate plateau potentials and can change the mode of cell firing (Major et al., 2008; Augustinaite et al., 2014; Grienberger et al., 2014). Elucidating this pattern within lamprey spinal neurons will inform how the location and timing of $\mathrm{Ca}^{2+}$ entry leads to $\mathrm{K}_{\mathrm{Ca}} 2$ channel activation, and furthermore, how synaptic activity distributed across a dendritic tree is integrated to produce cell rhythmicity. This, in turn, will facilitate our understanding of how intrinsic membrane properties combined with synaptic input causes synchronization between neurons of the CPG. Neuronal $\mathrm{Ca}^{2+}$ signaling can have distinct spatial components, easily identifiable using $\mathrm{Ca}^{2+}$ imaging. APs will lead to $\mathrm{Ca}^{2+}$ entry wherever VGCCs are driven above threshold, and can cause many regions of a cell (e.g., soma and proximal dendrites) to show synchronized increases in intracellular $\mathrm{Ca}^{2+}\left(\mathrm{Ca}^{2+}{ }_{i}\right)$. In contrast, local $\mathrm{Ca}^{2+}$ signaling domains (i.e., micro- and nano-domains) in dendrites can occur following neurotransmitter receptor activation (e.g., NMDAR), but also from VGCCs following depolarization from local synaptic potentials (Augustine et al., 2003). Synaptic signals are remarkably localized, confined to individual dendritic spines or discrete areas in dendritic shafts. For this reason, $\mathrm{Ca}^{2+}$ imaging can directly identify active synapses. Each type of $\mathrm{Ca}^{2+}$ signaling domain may be considered to be a distinct processing unit within a neuron because $\mathrm{Ca}^{2+}$ signals can regulate local $\mathrm{Ca}^{2+}$-dependent processes precisely where free $\mathrm{Ca}^{2+}$ levels transiently escape local buffering. However, $\mathrm{Ca}^{2+}$ signals exceeding this local threshold are transient- $\mathrm{Ca}^{2+}$ is rapidly buffered by $\mathrm{Ca}^{2+}$-binding proteins, and then extruded via membrane pumps, or sequestered in intracellular stores (Augustine et al., 2003; Berridge, 2006). This places temporal and spatial restrictions on diffusion of $\mathrm{Ca}^{2+}$ within neurons and is an important consideration when assessing the degree of localization. Dendritic morphology, like the presence of spines ( $\sim 1 \mu \mathrm{m}$ in length), is a large determinant for the extent of spread of $\mathrm{Ca}^{2+}$ because diffusion is restricted at the spine neck (Nimchinsky et al., 2002). Lamprey spinal neuron dendrites lack spines, but still posses fine compartments along dendritic shafts $(\sim 10 \mu \mathrm{m}$, see Figure 1; Viana di Prisco and Alford, 2004;
Alpert and Alford, 2013) that may theoretically serve a similar purpose - the local restriction of the flow of ions and intracellular messengers (Svoboda et al., 1996). Thus, morphology and the intrinsic properties of the dendritic membrane impacts $\mathrm{Ca}^{2+}$ dynamics and the integration of electrical and chemical signals.

The functional distinction between global and local $\mathrm{Ca}^{2+}$ signals and their associated topography is integral to single neuron computation necessary to generate rhythmic activity. The synaptic localization of $\mathrm{Ca}^{2+}$ signals may represent the encoding of distinct presynaptic information. Global, synchronized $\mathrm{Ca}^{2+}$ signals can be generated by back-propagating action potential (bAP)-driven VGCC activation in dendrites (Schiller et al., 1997; Stuart et al., 1997; Svoboda et al., 1997). When $\mathrm{Ca}^{2+}{ }_{i}$ is elevated during these events, the number of parallel computations being performed by the dendritic arbor is effectively reduced. In contrast, local and spatially distributed NMDAR-dependent synaptic $\mathrm{Ca}^{2+}$ signals reflect multiple discrete, simultaneous computations (Chen et al., 2011). Each synapse can thus be understood to be its own computational unit, capable of being selectively tuned to support distinct information arriving within a network.

Multiple, distinct routes can lead to $\mathrm{Ca}^{2+}$ entry. In behaving neurons within some networks, these mechanisms may work in concert, leading to nonlinear interactions between ion channels and $\mathrm{Ca}^{2+}$ sources when occurring simultaneously. For instance, following presynaptic release of glutamate, AMPA receptors (AMPARs), NMDARs and metabotropic glutamate receptors (mGluRs) may be activated in the postsynaptic compartment. AMPARs are responsible for fast depolarization, and can locally activate nearby VGCCs to cause $\mathrm{Ca}^{2+}$ entry. Local depolarization, or depolarization induced from bAPs can alleviate $\mathrm{Mg}^{2+}$ block of the NMDAR, facilitating $\mathrm{Ca}^{2+}$ influx during concurrent and subsequent release of glutamate at that synapse (Yuste and Denk, 1995; Nevian and Sakmann, 2004; Bloodgood and Sabatini, 2007). During bAPs, layer 5 pyramidal neurons have been shown to require tight spatial coupling between $\mathrm{Ca}^{2+}$ entry through R-type channels and $\mathrm{K}_{\mathrm{Ca}} 2$ channels in proximal dendrites and spines (Jones and Stuart, 2013). Group I mGluR activation can lead to the release of $\mathrm{Ca}^{2+}$ from internal stores (Frenguelli et al., 1993; Kettunen et al., 2002; Larkum et al., 2003; Topolnik et al., 2009; Plotkin et al., 2013). Release from internal stores has been shown to activate $\mathrm{Ca}^{2+}$-dependent $\mathrm{K}^{+}$channels in many neurons and species (Kawai and Watanabe, 1989; Akita and Kuba, 2000; Yamada et al., 2004; Faber, 2010; Nakamura and Yokotani, 2010). It is unknown if such combinatory mechanisms are present in lamprey spinal neurons, but lamprey neurons do possess all the necessary components. Indeed, specific agonists and antagonists acting on discrete components have well-described cellular and network effects (Alford et al., 2003). Any modulation of $\mathrm{Ca}^{2+}$ entry, either increasing or decreasing, within close proximity to $\mathrm{K}_{\mathrm{Ca}} 2$ channels, could impact subsequent channel activation and particular effects on the locomotor behavior. For example, an enhancement of $\mathrm{Ca}^{2+}$ could lead to early burst terminationan effect that, if it were to occur within many neurons simultaneously, would scale to the behavioral level to terminate muscle contraction earlier within the locomotor cycle. Upon repeated enhancements in $\mathrm{Ca}^{2+}$, during rhythmic activity, this could 
facilitate a fast swimming rhythm. Defining their roles while acting in concert is necessary to delineate how $\mathrm{Ca}^{2+}$ entry and $\mathrm{K}_{\mathrm{Ca}} 2$ activations drives oscillation generation.

The location of $\mathrm{Ca}^{2+}$ entry and the distance to its secondary effectors determines the efficacy with which $\mathrm{Ca}^{2+}$ will reach its target (Marrion and Tavalin, 1998). If the site of $\mathrm{Ca}^{2+}$ entry is located far from $\mathrm{K}_{\mathrm{Ca}} 2$ channels, then the probability of $\mathrm{Ca}^{2+}$ binding to a $\mathrm{K}_{\mathrm{Ca}} 2$ channel is diminished compared to its binding to other endogenous buffers that are located more proximally or are cytosolic and diffusible. Thus, a larger $\mathrm{Ca}^{2+}$ signal will be necessary to outcompete endogenous buffers. Conversely, if $\mathrm{K}_{\mathrm{Ca}} 2$ channels are located close to the site of $\mathrm{Ca}^{2+}$ entry, then depolarization will be quickly and locally counteracted by $\mathrm{K}^{+}$ activation. For $\mathrm{K}_{\mathrm{Ca}} 2$ channels to generate the mAHP, they must be sufficiently close to the site of $\mathrm{Ca}^{2+}$ entry generated by AP-driven VGCC activation. This functional coupling has been demonstrated in numerous species and cell types (Sah and Bekkers, 1996; Marrion and Tavalin, 1998; Wikström and El Manira, 1998; Faber and Sah, 2002; Bloodgood and Sabatini, 2007; Jones and Stuart, 2013). At present, the distance between the site of $\mathrm{Ca}^{2+}$ entry and $\mathrm{K}_{\mathrm{Ca}} 2$ channels can only be estimated based on differences between BAPTA and EGTA-mediated occlusion of $\mathrm{K}_{\mathrm{Ca}} 2$ activation in lamprey spinal VHNs. The range has been estimated to be between 20 and $>200 \mathrm{~nm}$ in multiple CNS neuron types depending on the target's affinity for $\mathrm{Ca}^{2+}$ (Fakler and Adelman, 2008). A recent measurement has suggested that $\mathrm{K}_{\mathrm{Ca}} 2$ channels activated following APs exhibit weak coupling to VGCCs, as they are occluded by EGTA, the slow $\mathrm{Ca}^{2+}$ buffer $\left(K_{\text {forward }}=1.5 \times 10^{6} \mathrm{M}^{-1} \mathrm{~s}^{-1}\right)$ (Roberts, 1993), placing the separation at greater than $\sim 100 \mathrm{~nm}$ in neocortical pyramidal neurons (Jones and Stuart, 2013). Occlusion of $\mathrm{K}_{\mathrm{Ca}} 2$ channel activation from NMDAR-dependent $\mathrm{Ca}^{2+}$ entry using BAPTA, the fast $\mathrm{Ca}^{2+}$ buffer $\left(K_{\text {forward }}=6 \times 10^{8} \mathrm{M}^{-1} \mathrm{~s}^{-1}\right)$ (Roberts, 1993), demonstrates a narrow range of 20-50 $\mathrm{nm}$ (Ngo-Anh et al., 2005), with experiments in lamprey suggesting similar degree of coupling (Alpert and Alford, 2013; Nanou et al., 2013).

For $\mathrm{K}_{\mathrm{Ca}} 2$ channels to repolarize NMDA-TTX $V_{m}$ oscillations, they must be activated by NMDAR-dependent $\mathrm{Ca}^{2+}$ entry. The subcellular expression of ion channels, including $\mathrm{K}_{\mathrm{Ca}} 2$ channels, is unknown in lamprey, while some spatial information has been detailed for mammalian hippocampal neurons. $\mathrm{K}_{\mathrm{Ca}} 2$ channel immunoreactivity demonstrates channel expression on dendritic spines in CA1 pyramidal neurons (Sailer et al., 2004; Ballesteros-Merino et al., 2012) in addition to shafts and soma in cultured mice hippocampal neurons (Ngo-Anh et al., 2005). Recently, however, using single-molecule atomic force microscopy with unprecedented spatial resolution ( $<10 \mathrm{~nm}$ (Müller et al., $2009)$ ), $\mathrm{K}_{\mathrm{Ca}} 2$ channels were shown to be in high concentration in the dendrites relative to the soma of live, cultured hippocampal neurons (Maciaszek et al., 2012). Functional evidence for complexes of NMDARs and $\mathrm{K}_{\mathrm{Ca}} 2$ channels has been demonstrated in many species and cell types. NMDAR-mediated field potentials are potentiated by apamin in CA1 hippocampal pyramidal neurons ( $\mathrm{Gu}$ et al., 2008). Direct NMDA application leads to an inward current followed by an apamin-dependent outward current (Shah and Haylett, 2002; Nanou et al., 2013). Apamin potentiates both synaptically evoked NMDAR EPSPs on CA1 dendrites, while also potentiating apical spine $\mathrm{Ca}^{2+}$ transients (Ngo-Anh et al., 2005). However, it was later demonstrated using 2-photon glutamate uncaging that $\mathrm{Ca}^{2+}$ entry via $\mathrm{R}$ type VGCCs is necessary and directly coupled to $\mathrm{K}_{\mathrm{Ca}} 2$ channels at these spine synapses, whereas NMDAR-dependent $\mathrm{Ca}^{2+}$ is insufficient to activate $\mathrm{K}_{\mathrm{Ca}} 2$ channels (Bloodgood and Sabatini, 2007). This discrepancy was recently reconciled with experiments demonstrating that $\mathrm{K}_{\mathrm{v}} 4$.2-containing channels and NMDARs are differentially coupled to R-type VGCCs and NMDARs, respectively (Wang et al., 2014b). Furthermore, $\mathrm{K}_{\mathrm{Ca}} 2$ channel activation by NMDAR-induced spine $\mathrm{Ca}^{2+}$ transients is also occluded by BAPTA, but not by EGTA, indicating a very close physical coupling of the route of $\mathrm{Ca}^{2+}$ entry and the $\mathrm{K}_{\mathrm{Ca}} 2$ channel (Ngo-Anh et al., 2005) - a similar role for NMDARs and $\mathrm{K}_{\mathrm{Ca}} 2$ channel is also demonstrated in the lateral amygdala (Faber et al., 2005) and in layer 5 neocortical pyramidal neurons (Faber, 2010). Furthermore, overexpression of $\mathrm{K}_{\mathrm{Ca}} 2$ channels depresses synaptically evoked glutamatergic EPSPs (Hammond et al., 2006). Due to the role of NMDAR-dependent $\mathrm{Ca}^{2+}$ entry in synaptic plasticity, blockade of $\mathrm{K}_{\mathrm{Ca}} 2$ channels facilitates the induction of LTP (Stackman et al., 2002) because this, in turn, facilitates $\mathrm{Ca}^{2+}$ entry through NMDARs, presumably by augmenting depolarization. Similarly, downregulation of $\mathrm{K}_{\mathrm{Ca}} 2$ channels is necessary for amplification of dendritic responses in a compartment- (Ohtsuki et al., 2012) or synapse-specific (Lin et al., 2008) manner, partially explaining the subsequent potentiation of current.

Thus, the very precise subcellular targeting of $\mathrm{K}_{\mathrm{Ca}} 2$ channels to ion channels responsible for $\mathrm{Ca}^{2+}$ transients (demonstrated by sensitivity to rapid $\mathrm{Ca}^{2+}$ binding by BAPTA) will profoundly impact cell firing rates, dendritic integration, and processing both in real-time during individual cycles of locomotor activity, but also in the long-term. The molecular complexing of $\mathrm{Ca}^{2+}$ sources to secondary effector proteins, like $\mathrm{K}_{\mathrm{Ca}} 2$ in lamprey, will consequently impact spike-timing through activation of the mAHP (Buchanan and Grillner, 1987; Wallén and Grillner, 1987; Alford and Williams, 1989; Wallén et al., 1989; Hill et al., 1992; Hochman et al., 1994; Wall and Dale, 1995; Buchanan, 2001; Harris-Warrick, 2002; Wang, 2010) in addition to burst termination (El Manira et al., 1994; Alpert and Alford, 2013; Nanou et al., 2013) during NMDAR-dependent rhythmic activity. These intrinsic membrane properties have direct consequences on spinal neuron output, and hence the locomotor pattern generation of the spinal network.

\section{EVIDENCE FOR A DENDRITIC MECHANISM OF INTRINSIC OSCILLATIONS IN THE CNS}

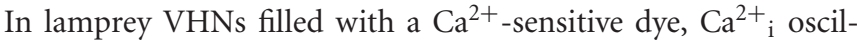
lates in-phase with VR bursts and $V_{m}$ oscillations, varying with different NMDA-induced swimming speeds (Bacskai et al., 1995; Viana di Prisco and Alford, 2004). In contrast, during activity that was subthreshold to action potential firing, the soma showed no $\mathrm{Ca}^{2+}$ fluctuations, while the dendritic fluorescence oscillated in-phase with the $V_{m}$, with the largest oscillations in $\mathrm{Ca}^{2+}{ }_{\mathrm{i}}$ found in the distal dendrites. When spiking, the somatic $\mathrm{Ca}^{2+}$ then showed spike-dependent activity, which is in-phase 
with $V_{m}$, oscillations because spiking occurs at the depolarized phase of activity. However, despite spikes also elevating dendritic $\mathrm{Ca}^{2+}$ signals, the largest increases in fluorescence occurred in the soma, likely reflecting somatically localized VGCC activation (Viana di Prisco and Alford, 2004). The elevated dendritic signals could be due to dendritic VGCC activation, enhanced NMDAR conductance due to local depolarization from bAPs, or both. The phase relationships of the $\mathrm{Ca}^{2+}$ oscillations in dendrites relative to $V_{m}$ oscillations suggest that these $\mathrm{Ca}^{2+}$ signals are responsible for $\mathrm{K}_{\mathrm{Ca}} 2$ activation, and hence repolarization of the membrane. This result along with experiments discussed earlier (Grillner and Wallén, 1985; Wallén and Grillner, 1987) provide substantial evidence that NMDAR-dependent $\mathrm{Ca}^{2+}$ entry underlies the repolarization of $V_{m}$ oscillations.

Results from experiments in which the spinal CPG is activated by application of exogenous NMDA also imply that rhythmic $V_{m}$ oscillations are driven by phasic $\mathrm{Ca}^{2+}$ oscillations that are synchronized across large regions, if not all, of the dendritic tree (Figure 4). However, during bath-application of NMDA, both synaptic and extrasynaptic NMDARs are activated and thus the dendritic $\mathrm{Ca}^{2+}$ signals are likely to be much less spatially and temporally constrained than signals driven during physiologically evoked locomotion. This forces the concerted activation of all NMDARs when the dendritic membrane is depolarized, which would consequently synchronize all parts of the neuron. Thus, it is unclear if during NMDA-evoked locomotion whether network synchrony is driven by synchronized presynaptic activity caused directly by bath-applied NMDA, or if rhythmicity emerges from more physiologically derived synaptic integration of distributed input and is then transformed into well-defined $V_{m}$ oscillations. Similarly, the spatiotemporal profile of dendritic activation and $\mathrm{Ca}^{2+}$ signaling underlying membrane potential oscillations during locomotion remains unknown. This profile will, however, be particularly important for understanding how membrane properties drive the activity of the network.

Synchronized oscillations are widespread in the CNS. While critical for the generation of motor rhythms, they are key components of many neural systems. In the neocortex and hippocampus, oscillations at the cellular level are correlated with synchrony at the network level (Contreras and Steriade, 1995) and are thought to underlie cognitive processes such as working memory (Llinás, 1988), spatial navigation, and memory encoding (Buzsáki and Moser, 2013). Both theoretical approaches and experimental evidence suggest that the cellular basis for working memory relies upon persistent firing of networks generated by recurrent synaptic excitation of NMDARs due to its slow kinetics and voltage-dependency (Lisman et al., 1998; Wang, 2001) conferring bistability (Durstewitz et al., 2000). NMDA-TTX oscillations are also found in midbrain dopamine neurons (Johnson et al., 1992; Deister et al., 2009) cat neocortical pyramidal neurons (Flatman et al., 1986), rat inferior olivary neurons (Placantonakis and Welsh, 2001), Xenopus RS neurons (Li et al., 2010), guineau pig and rat trigeminal motor neurons (Kim and Chandler, 1995; Hsiao et al., 2002), and rat and cat thalamocortical neurons (Leresche et al., 1991), demonstrating a similar intrinsic oscillatory mechanism to lamprey spinal neurons.

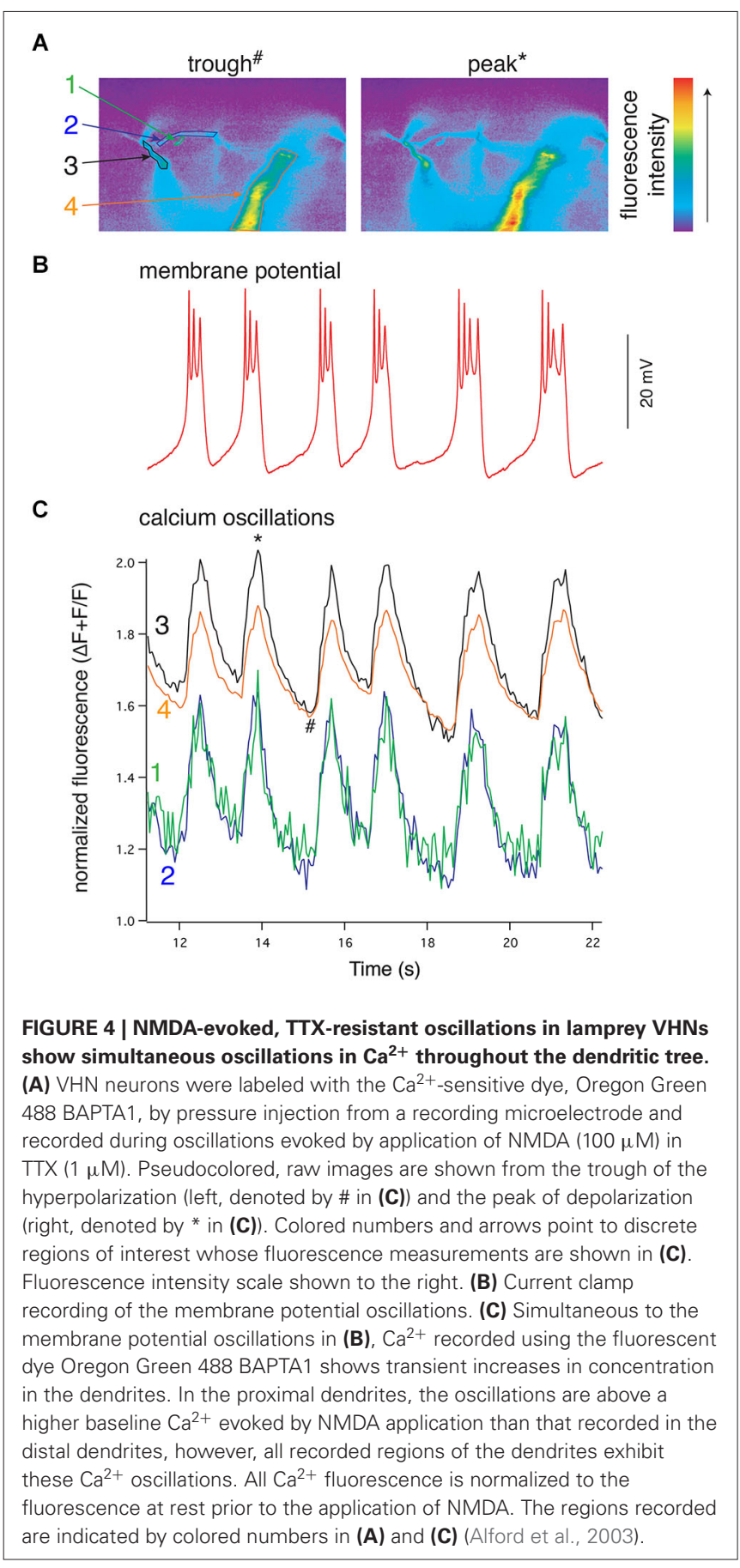

Although arrangements involving NMDARs and $\mathrm{K}_{\mathrm{Ca}} 2$ channels have been shown in many other systems and synapses, their functions have not been expressly linked to specific behaviors or to rhythm generation, but rather have been proposed to serve a more generalized mechanism for tempering synaptic potentials and synaptic plasticity (Shah and Haylett, 2002; Stackman et al., 2002; Maher and Westbrook, 2005; Ngo-Anh et al., 2005; Gu et al., 2008; Lin et al., 2008; Faber, 2010; Harvey-Girard and Maler, 2013). Apamin or intracellular dialysis with BAPTA prolongs glutamate-induced plateau potentials and $\mathrm{Ca}^{2+}$ transients 
in CA1 pyramidal neuron distal apical dendrites (Wei et al., 2001; Cai et al., 2004), but these plateau potentials are produced through a combination of R-type VGCCs, NMDARs and bAPs (Takahashi and Magee, 2009), and thus does not explicitly link $\mathrm{Ca}^{2+}$ entry via NMDARs to $\mathrm{K}_{\mathrm{Ca}} 2$ activation. NMDARdependent activation of $\mathrm{K}_{\mathrm{Ca}} 2$ channels at layer 5 pyramidal neuron synapses (Faber, 2010) indicates the necessary components are present, but the mechanism of dendritic oscillation generation has yet to be explored. Recently, a dendritic mechanism for synchronizing spatially disparate synaptic input has been described in CA1 pyramidal neurons, which has implications in the synchronization of hippocampal networks (Vaidya and Johnston, 2013). In lamprey spinal neurons, the nonlinear dynamics of the NMDAR combined with its spatial coupling to $\mathrm{K}_{\mathrm{Ca}} 2$ channels confers $V_{m}$ bistability, enabling these neurons to be oscillators to synchronize spinal networks for rhythmic locomotion.

\section{EVIDENCE FOR CLOSE COUPLING OF NMDARS AND $\mathrm{K}_{\mathrm{Ca}} 2$ CHANNELS}

If NMDARs are the primary route of $\mathrm{Ca}^{2+}$ entry necessary for repolarization, then synaptically activated NMDARs will evoke highly localized $\mathrm{Ca}^{2+}$ entry within spinal neuron dendrites, and this $\mathrm{Ca}^{2+}$ must be located sufficiently close to $\mathrm{K}_{\mathrm{Ca}} 2$ channels to activate an outward current. EIN stimulation causes localized, NMDAR-dependent $\mathrm{Ca}^{2+}$ entry in VHN dendrites (Alpert and Alford, 2013). NMDAR EPSCs are sufficient to activate $\mathrm{K}^{+}$currents, which are blocked by the $\mathrm{K}_{\mathrm{Ca}} 2$ blockers, apamin and UCL 1684, or following whole cell dialysis with BAPTA. In contrast, EGTA dialysis is ineffective at preventing $\mathrm{K}_{\mathrm{Ca}} 2$ activation (Nanou et al., 2013). Furthermore, BAPTA also prevents repolarization from depolarized plateaus in oscillating neurons induced by NMDA in TTX, whereas those dialyzed with EGTA are able to repeatedly repolarize (Alpert and Alford, 2013). Since BAPTA, but not EGTA, occludes the binding of $\mathrm{Ca}^{2+}$ to secondary effectors, presumably $\mathrm{K}_{\mathrm{Ca}} 2$, the channel must be located physically close to the site of $\mathrm{Ca}^{2+}$ entry (Marrion and Tavalin, 1998; Ngo-Anh et al., 2005; Fakler and Adelman, 2008).

Any possible role for VGCCs in directly providing $\mathrm{Ca}^{2+}$ to drive the repolarization is somewhat limited by the voltage threshold of activation relative to the $V_{m}$ oscillation range. Lamprey VHNs contain multiple subtypes of VGCCs including N-, P/Q-, and L-type channels with varying contributions to depolarization-evoked whole-cell currents1 (El Manira and Bussières, 1997) and presumably distinct cellular localizations (Llinás and Yarom, 1981; Llinás, 1988; Westenbroek et al., 1990, 1992; Mills et al., 1994; Isope et al., 2012). In cultured lamprey spinal neurons, $\mathrm{N}$ - and $\mathrm{P} / \mathrm{Q}$-type channels account for $\sim 75 \%$ of the total whole cell VGCC current, while L-type current contributes $\sim 15 \%$ with the residual $\mathrm{Ca}^{2+}$ current uncharacterized, but sensitive to $\mathrm{Cd}^{2+}$, the non-specific VGCC blocker (El Manira and Bussières, 1997). However, these values are likely impacted by reduced dendritic arbors in culture and space clamp issues common to somatic recordings. $\mathrm{Cd}^{2+}$ abolishes whole-cell current in situ, yet NMDA-TTX oscillations persist in $\mathrm{Cd}^{2+}$ (Alpert and Alford, 2013), while simultaneous $\mathrm{Ca}^{2+}{ }_{\mathrm{i}}$ oscillations are insensitive to selective blockade of $\mathrm{N}$ - and P/Q-type VGCCs. L-type channels couple to $\mathrm{K}_{\mathrm{Ca}} 2$ channels in hippocampal pyramidal neurons (Marrion and Tavalin, 1998), while $\mathrm{Ca}^{2+}$ imaging suggests that this coupling may exist in a subset of dendritic loci in lamprey (Wang et al., 2013) because modulation of L-type channels impacts $\mathrm{Ca}^{2+}$ oscillations and the $V_{m}$ oscillation waveform (Wang et al., 2014a). The current-voltage (I-V) relationship of VGCCs in VHNs shows minimal activation at $-60 \mathrm{mV}$, with significant activation occurring between $-40 \mathrm{mV}$ and $-30 \mathrm{mV}$, peaking between -10 and $0 \mathrm{mV}$ ( $\mathrm{El}$ Manira and Bussières, 1997; Alpert and Alford, 2013). Interestingly, the same $V_{m}$ where VGCCs become activated, $-40 \mathrm{mV}$, is also the peak plateau potential reached during membrane potential oscillations in NMDA (Alpert and Alford, 2013). Thus, for the majority of VHNs, the neurons oscillate subthreshold to the VGCC activation thresholds except for the initial transient peak of the oscillation amplitude. Indeed, NMDA application reveals a depolarizing step-evoked inward current that occurs within the $V_{m}$ oscillation range at substantially more hyperpolarized $V_{m} s$ than currents mediated by VGCCs in these neurons. Similarly, $\mathrm{Ca}^{2+}$-imaging indicates that $\mathrm{Ca}^{2+}$ entry within the oscillation range is robustly potentiated and dominated by NMDAR-dependent $\mathrm{Ca}^{2+}$ entry (Alpert and Alford, 2013). During voltage steps in NMDA, biphasic currents are generated. This NMDA-induced inward current followed by an outward current is present within the oscillation range (i.e., below $-40 \mathrm{mV}$ ) and blocked by BAPTA, but not EGTA, again reflecting a close functional coupling between NMDAR current and presumably $\mathrm{K}_{\mathrm{Ca}} 2$ channel activation leading to the outward current. Therefore, both $V_{m}$ and $\mathrm{Ca}^{2+}{ }_{\mathrm{i}}$ oscillations are driven through a dendritic mechanism requiring closely apposed ensembles of NMDARs and $\mathrm{K}_{\mathrm{Ca}} 2$ channels and little contribution of $\mathrm{Ca}^{2+}$ from VGCCs.

\section{DENDRITIC STRUCTURE AND SYNAPTIC INTEGRATION OF PRESYNAPTIC MICROCIRCUITRY OF VENTRAL HORN NEURONS}

In general, the origin of presynaptic input, synapse location within the dendritic tree, and electrotonic distance to soma informs the computation performed by the postsynaptic neuron. Spatially and anatomically compartmentalized dendritic targeting by presynaptic axons is found in many vertebrate neural circuits including the tectum (Bollmann and Engert, 2009), hippocampus (Pouille and Scanziani, 2004; Jarsky et al., 2005), neocortex (Weiler et al., 2008; Anderson et al., 2010), and cerebellum (Ito, 2006; Gao et al., 2012). Variability in presynaptic activity can lead to variation of the topology of $\mathrm{Ca}^{2+}$ signaling postsynaptically where it may be encoded predictably onto distinct dendritic compartments (Bollmann and Engert, 2009; Xu et al., 2012). In other instances, $\mathrm{Ca}^{2+}$ signaling is unpredictably encoded and may demonstrate extremely heterogeneous expression of activity, even at neighboring synapses (Chen et al., 2011). Global $\mathrm{Ca}^{2+}$ signals generated by AP-induced VGCC activation may appear qualitatively similar to those generated from convergent presynaptic activation leading to a global rise in $\mathrm{Ca}^{2+}$. However, the computation performed by a neuron is distinct, depending on the modality of $\mathrm{Ca}^{2+}$ signaling. Somatic signals provide intrinsic information about cell firing, while local, synaptic 
signals inform about the spatial and functional connectivity of the network and its activation state. Indeed, the computational ability of a neuron's dendrites is intimately tied to and ultimately informed by presynaptic inputs, whose activity leads to discernable behavioral functions postsynaptically (Jia et al., 2010). In hippocampal and neocortical pyramidal neurons, neighboring dendritic synapses are more likely to be activated synchronously than synapses spaced further apart (Kleindienst et al., 2011; Takahashi et al., 2012). This functional clustering is NMDARdependent and likely due to synchronized and convergent targeting of multiple presynaptic axons projecting to the recorded neurons, rather than a single presynaptic axon making multiple contacts. Such functional clustering may be important for circuit orchestration during development (Kleindienst et al., 2011) and experience-dependent synaptic plasticity (Makino and Malinow, 2011). Furthermore, NMDAR activation is essential for nonlinear boosting of temporally and spatially integrated synaptic potentials (Polsky et al., 2004). Synaptic potentials arriving at the soma from discrete synaptic events can vary according to degree of clustering (Losonczy and Magee, 2006) and the direction and velocity of synaptic input along single dendritic branches (Branco et al., 2010). The patterning of synaptic input has profound consequences on $\mathrm{Ca}^{2+}{ }_{\mathrm{i}}$ and this "within dendritic branch" form of computation is NMDAR-dependent. Furthermore, synaptic plasticity - the $\mathrm{Ca}^{2+}$-dependent change in strength of a synapsecan occur selectively at a single synapse (Matsuzaki et al., 2004; Enoki et al., 2009; Makino and Malinow, 2011). Thus, postsynaptic responses to $\mathrm{Ca}^{2+}$, and hence dendritic computational capacity (Poirazi and Mel, 2001), are highly dynamic and depend on presynaptic input and subsequent post-synaptic $\mathrm{Ca}^{2+}$ signals as well as the function of the circuit in which the neuron is embedded.

Discrete targeting provides neurons with more processing power (Häusser and Mel, 2003; Polsky et al., 2004) by integrating origin-specific, segregated streams of presynaptic information. This is further enhanced as the location and expression of various voltage-gated ion channels and synaptic receptors varies between different types of neurons but also subcellularly, between different regions of a single neuron (Migliore and Shepherd, 2002; Williams and Stuart, 2003; Jones et al., 2014). Such circuit and dendrite dynamics may also be present in spinal networks controlling movement. A well-defined topographic map of spinal motoneuron recruitment in larval zebrafish proceeds from the ventral to dorsal spinal cord as swimming frequency increases (McLean et al., 2007) and neurons are recruited functionally according to intrinsic rhythm-generating capabilities and requirement for presynaptic oscillatory synaptic drive (Menelaou and McLean, 2012). However, the interneurons that drive motoneuron recruitment demonstrate more complex activation patterns (McLean et al., 2008). The spatial targeting of motoneuron or interneuron dendrites and the integration of synaptic inputs conferring rhythmicity have yet to be defined, but dendritic filopodial activity follows a topographic pattern that maps (Kishore and Fetcho, 2013) onto their recruitment order (McLean et al., 2007) and subsequent electrical activity level, delineating behavioral function to dendrites located in discrete regions along the dorsoventral axis. Thus, the location and targeting of specific dendritic subregions by spatially defined presynaptic neurons may suggest a functional role for individual dendritic branches (Wei et al., 2001; Poirazi et al., 2003; Branco and Häusser, 2010), or perhaps even synapses (Jia et al., 2010), in the output of a given motor neuron.

Dendrite distribution has been shown to differ for motoneurons innervating distinct muscles in the chick spinal cord (Okado et al., 1990). Mice motoneuron dendrites are genetically oriented to particular spinal territories, which influence the connectivity patterns of their proprioceptive afferent inputs (Vrieseling and Arber, 2006). The targeting of dendrites into specific lamina provides distinct opportunities for different classes of presynaptic excitatory and inhibitory interneurons to also target different dendritic regions (Kosugi et al., 2013). Drosophila motoneuron dendrites are topographically organized whereby individual neurons genetically target their dendrites to precise anatomical territories centrally, representing their muscle distribution peripherally (Landgraf et al., 2003; Brierley et al., 2009). Within a single dendritic tree there can be a heterogeneous patterning of excitatory synapses (Mauss et al., 2009) and, furthermore, distinct dendritic subtrees can target discrete regions of the neuropil (Vonhoff and Duch, 2010). Therefore, organizational principles orchestrating spinal circuits controlling locomotion are subject to genetic, developmental, and activity-dependent specificity, but determining the function of distinct subcellular targeting requires further investigation.

\section{SYNAPSE-SPECIFICITY OF $\mathrm{K}_{\mathrm{Ca}} 2$ CHANNELS IS BEHAVIORALLY RELEVANT}

The precise coupling of synaptically activated receptors and secondarily activated ion channels may complement anatomical specificity of excitatory connections. The behavioral importance of this coupling becomes evident when considering how descending brainstem RS neuron drive interacts with the spinal cord CPG. In vertebrates, $\mathrm{RS}$ neurons receive feedback modulation from the spinal CPG that causes them to fire in-phase with the rostral spinal segments (Kasicki et al., 1989; Sirota et al., 2000; Dubuc et al., 2008). This phenomenon creates a paradox with respect to RS innervation of the spinal CPG. In lamprey, each VHN receives input from both local circuit interneurons (glutamatergic and glycinergic) (Buchanan, 1982; Buchanan and Grillner, 1987) and descending RS axons (glutamatergic) (Buchanan et al., 1987; Brodin et al., 1988). Thus, a single VHN may receive two distinct types of glutamatergic contacts. Since the animal creates a rostro-caudal phase lag of $360^{\circ}$ from head to tail (Wallén and Williams, 1984), substantial regions of the spinal cord are necessarily out-of-phase with RS neuron firing. Furthermore, as the fish swims, RS axon APs are initiated in the brainstem and project throughout the length of the spinal cord where they excite local CPGs. The AP propagation rate is faster than the speed of the mechanical wave driven by the propagation of neural excitation by segmental CPGs $(\sim 10 \mathrm{~Hz}$ traveling wave). Thus, there are two traveling waves, RS axon-generated AP propagation and CPG neural waves, which are out-of-phase across substantial rostro-caudal regions of the spinal cord and whose phase mismatch varies with locomotor frequency (Figure 5). This phase mismatch precludes RS axons from being phase-locked 


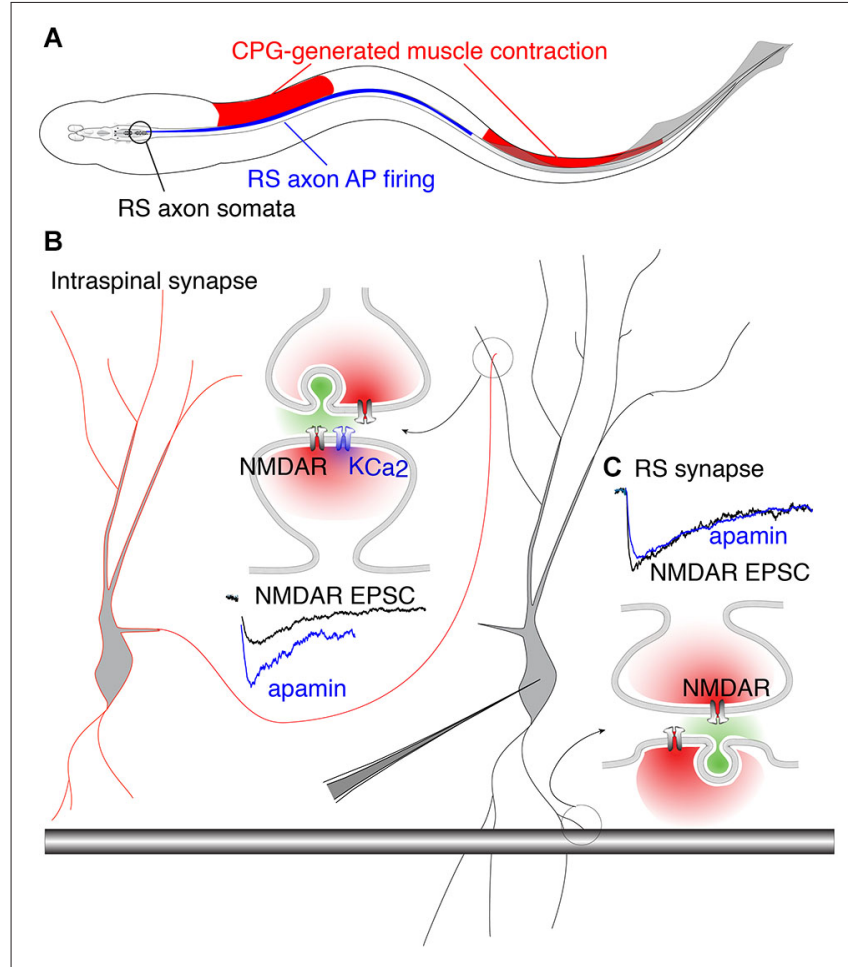

FIGURE 5 | Phase-matched and phase-mismatched excitatory synapses in the spinal cord of lamprey. (A) As the lamprey swims it generates a traveling wave from head to tail. The sinusoidal body curvature illustrated here represents a single moment in body movement during a bout of swimming. During swimming, command excitation is continually provided by RS axons whose somata in the brainstem (encircled in black) fire (blue) in phase with the rostral spinal CPG neurons. This is illustrated by the rostro-caudal overlap of red and blue. It is the output of spinal segments that causes ipsilateral muscle contraction (red). Due to the speed at which the action potential (AP) propagates along RS axons, the AP invades more caudal areas of the spinal cord whose associated muscles do not undergo contraction because the CPG wave (responsible for contraction) travels at a delay relative to the AP. This leads to regions along the spinal cord where AP firing overlaps with inhibited musculature (illustrated by overlap of blue and white regions in the middle). This would predictably lead VHN excitation at inappropriate times during the swim cycle. This phase mismatch between RS axons and CPG neurons may be avoided by synapse-specific $\mathrm{K}_{\mathrm{Ca}} 2$ channel activation. (B) Circuit model in which excitation from EINs (red outlined cell) projects to other VHNs (black outlined cell) locally within the spinal cord. NMDAR currents from these neurons (black trace, NMDAR EPSC) are enhanced by the addition of apamin, the specific $\mathrm{K}_{\mathrm{Ca}} 2$ channel antagonist, to block $\mathrm{K}_{\mathrm{Ca}} 2$ currents (blue trace). (C) RS synapses from large descending axons (black shaded bar) which project throughout the spinal cord, show NMDAR currents (black trace, NMDAR EPSC) that are unaffected by apamin (blue trace) (Alpert and Alford, 2013).

with VHNs, thus removing the need for pre- and postsynaptic synchronization conferred by coupling of NMDARs and $\mathrm{K}_{\mathrm{Ca}} 2$ channel activation.

Accordingly, it may be considered problematic for RS synapses expressing NMDARs to be coupled to $\mathrm{K}_{\mathrm{Ca}} 2$ channels, which would instill a strict phase-relationship between the pre- and post-synaptic neuron via excitation-inhibition coupling. In contrast, spinal EINs are appropriately phase-locked to their targets because the extent of their spinal projections are limited (Buchanan et al., 1989). This hypothesis is supported by experiments utilizing paired recordings between RS axons and VHNs, demonstrating that postsynaptic NMDAR-mediated responses are insensitive to apamin (Cangiano et al., 2002; Alpert and Alford, 2013). In contrast, glutamatergic synapses between EINs and other VHNs within the spinal cord exhibit strong NMDAR coupling to $\mathrm{K}_{\mathrm{Ca}} 2$ channels (Alpert and Alford, 2013; Nanou et al., 2013), conferring excitation-inhibition coupling and phase-locking as the CPG waves propagate between segments. Such synapse-specificity emphasizes the highly localized nature of dendritic $\mathrm{Ca}^{2+}$ signals and the profound importance for restricting $\mathrm{Ca}^{2+}$ entry within local domains (Figure 5). Within this framework, the synapse-specificity of $\mathrm{K}_{\mathrm{Ca}} 2$ channel activation is crucial for creating synchrony between neurons of the spinal network. Thus, the synaptic localization of the $\mathrm{K}_{\mathrm{Ca}} 2$ channel coupled to NMDARs is not just important for opposing depolarization, but together with the precise function of the presynaptic neuron, establish the foundation for generating network rhythmicity.

\section{NEUROMODULATION OF K $\mathrm{Ca}_{\mathrm{a}} 2$ CHANNELS MEDIATING LOCOMOTION}

Locomotion is also activated and modulated by monoaminergic systems. Bath-applied serotonin (5-HT), alone or within a cocktail of monoamines, can activate locomotion and fictive locomotion in many preparations (Cazalets et al., 1992; Rossignol et al., 2002). Like glutamate, spinal release of 5-HT originates from both intraspinal (Schotland et al., 1995, 1996; Zhang and Grillner, 2000) and brainstem neurons (Zhang et al., 1996; Abalo et al., 2007; Antri et al., 2008; Barreiro-Iglesias et al., 2008). In lampreys, bath-applied 5-HT has a well-defined modulatory effect on the CPG-it slows ventral root bursting during both spinal exogenous agonist-evoked (Wikström et al., 1995) and brainstemevoked locomotion (Gerachshenko et al., 2009). 5-HT mediates its effects both pre- and post-synaptically through mechanistically distinct but behaviorally convergent effects. Postsynaptically, 5-HT modifies the activation of $\mathrm{K}_{\mathrm{Ca}} 2$ channels. This postsynaptic effect is mediated at two distinct subcellular sites. 5-HT suppresses burst termination during fictive locomotion induced by NMDA (Harris-Warrick and Cohen, 1985), an effect present during NMDA-TTX driven intrinsic oscillations (Wallén et al., 1989) and which is analogous to blockade of $\mathrm{K}_{\mathrm{Ca}} 2$ channels with apamin (El Manira et al., 1994) or UCL 1684 (Alpert and Alford, 2013). This prolongation of the oscillation may be mediated by direct interaction of $5-\mathrm{HT}$ receptors on $\mathrm{K}_{\mathrm{Ca}} 2$ channels, or alternatively, via an indirect inhibition of NMDARs (Schotland and Grillner, 1993) or VGCCs (Wang et al., 2014a) supplying $\mathrm{Ca}^{2+}$ for $\mathrm{K}_{\mathrm{Ca}} 2$ channels responsible for the repolarization. Interestingly, the effects of 5-HT are absent when the network is activated by kainate, which will not activate NMDARs directly. This suggests that NMDAR-dependent $\mathrm{Ca}^{2+}$ entry contributing to burst termination (Alpert and Alford, 2013; Nanou et al., 2013) is necessary for 5-HT to modulate the oscillation and that 5-HT receptors inhibit $\mathrm{K}_{\mathrm{Ca}} 2$ channels activated directly by NMDARmediated $\mathrm{Ca}^{2+}$ permeation.

In addition to effects of 5-HT directly on NMDAR-mediated oscillations, 5- $\mathrm{HT}_{1 \mathrm{~A}}$ receptors (Wikström et al., 1995) inhibit N-type VGCCs (Hill et al., 2003), reducing $\mathrm{Ca}^{2+}$ necessary for 
$\mathrm{K}_{\mathrm{Ca}} 2$ channel activation involved in mAHP (Wikström and El Manira, 1998). This effect is accordingly limited to individual neurons that spike repetitively during locomotion (or fictive locomotion). Thus, 5-HT interactions with $\mathrm{K}_{\mathrm{Ca}} 2$ channels are important in controlling firing rates in lamprey (Wallén et al., 1989; Hill et al., 1992; Meer and Buchanan, 1992) as well as other systems, but are also integral to the ionic mechanism contributing to NMDAR-dependent oscillatory properties (Harris-Warrick and Cohen, 1985; El Manira et al., 1994; Alpert and Alford, 2013; Nanou et al., 2013).

Presynaptically, 5-HT modulates glutamate release from intraspinal connections (e.g., EIN-VHN synapses) as well as from RS command neurons (Buchanan and Grillner, 1991; Blackmer et al., 2001, 2005). This effect mediated by $5-\mathrm{HT}_{1 \mathrm{~B}}$ receptors acts synergistically with the effects on $\mathrm{K}_{\mathrm{Ca}} 2$ channels. It also lengthens the locomotor burst duration during agonist- and (Schwartz et al., 2005) brainstem-evoked locomotion (Gerachshenko et al., 2009) by blocking synaptotagmin/SNARE complex interactions (Blackmer et al., 2005). This reduces cleft glutamate concentration, which leads to a selective reduction of AMPAR activation because NMDARs respond to low glutamate cleft concentrations more readily than do AMPARs (Patneau and Mayer, 1990; Choi et al., 2000; Schwartz et al., 2007). Sustained NMDAR activation combined with reduced AMPAR activation slows bursting recorded during fictive locomotion. This is similar to pharmacologically induced locomotion, which shows slower burst rates in NMDA compared to AMPA or kainate (Brodin et al., 1985; Alford and Grillner, 1990). It may in part be attributed to the slow and fast kinetics of NMDARs and AMPARs, respectively (Alford and Grillner, 1990), but is also a function of the spinal network in which repetitive activation that causes augmenting synaptic responses as seen in 5-HT favors slower rates of fictive locomotion (Kozlov et al., 2001; Svensson et al., 2001). Therefore, the complement of excitation of different glutamate receptors on VHN dendrites and the subsequent integration of those inputs, in conjunction with $\mathrm{K}_{\mathrm{Ca}} 2$ channels, is subject to serotonergic modulation of both synaptic transmission and intrinsic membrane properties. These very different effects of modulators impacting synaptic function and $\mathrm{K}_{\mathrm{Ca}} 2$ converge to influence the output of single neurons that scale to alter motor output.

Thus, the serotonergic system in the spinal cord plays a crucial role in modulating the output of the spinal network. While these results, whether mediated by pre- (Schwartz et al., 2005; Gerachshenko et al., 2009) or postsynaptic (Harris-Warrick and Cohen, 1985; Wallén et al., 1989; Wikström et al., 1995) 5-HT receptors explain effects of exogenous 5-HT, pharmacological application obscures crucial information regarding the spatiotemporal pattern of 5-HT release during swimming. Nevertheless, it is clear that 5-HT has profound effects on neural patterns and phase relationships within the spinal cord during locomotion and that this effect is substantially mediated through effects on $\mathrm{K}_{\mathrm{Ca}} 2$ channel activation.

\section{IMPORTANCE OF STUDYING DENDRITIC PROPERTIES WITHIN A BEHAVING NETWORK}

In all vertebrates, 5-HT and glutamate applied exogenously can initiate and influence locomotor-like activity. While it is remarkable that systemic drug application can reliably produce ethologically relevant locomotor patterns in lamprey (Sigvardt et al., 1985) and in other model systems (Rossignol et al., 1998; Kyriakatos et al., 2011), NMDARs in vivo are not physiologically activated by a tonic and diffuse release of glutamate. Instead, the release of neurotransmitter and subsequent receptor binding is exquisitely targeted to discrete postsynaptic loci with temporal precision. The physiological activation of NMDARs in any circuit is almost entirely mediated by the synaptic release of glutamate. This will only occur at synapses, and only following presynaptic release of glutamate at those synapses. This constrains the activation of NMDARs spatially and temporally, as well as the $\mathrm{K}_{\mathrm{Ca}} 2$ channels that are subsequently activated.

While pharmacological activation of the spinal network is presumably far from physiological, it has remained to be demonstrated just how distinct this artificial induction is from supraspinal control of descending command neurons and subsequent spinal CPG activation. It is important to note that generating rhythmic activity and appropriate phase coupling has many theoretical solutions (Wallén et al., 1992; Williams, 1992). In the spinal network that generates swimming, there can be multiple pathways which achieve a similar behavioral mode (Menelaou and McLean, 2012), an idea that emerged from the study of invertebrate CPGs (Marder and Bucher, 2007). In Xenopus larval tadpoles, there may be little specificity in anatomical connections early in development ( $\mathrm{Li}$ et al., 2007) suggesting that precise dendritic targeting is not necessary for functional circuit formation. Instead, a very basic scaffolding of neuronal connections is sufficient to construct early behaviors (Roberts et al., 2014). However, the specificity of microcircuit connectivity is subject to change. Synapses are plastic as is the dendritic architecture (Kishore and Fetcho, 2013). Nevertheless, synaptic connectivity and subsequent location-dependent dendritic integration is paramount to neural computation within microcircuits controlling behavior.

Furthermore, our understanding of how monoamines in general and 5-HT in particular act in vivo is even less certain than glutamate because exogenous application of these modulators over an artificially and pharmacologically activated network merely compounds errors and cannot match physiological release. Indeed, monoamine cocktails with glutamate agonists evoke spinal network activity (Rossignol et al., 1998; Masino et al., 2012) and when applied individually to active networks, monoamines modulate network activity (Barbeau and Rossignol, 1990; Rossignol et al., 1998). To develop a comprehensive understanding of the true pattern of synaptic drive to spinal neurons and microcircuits requires a more physiological method of activation of these spinal circuits than has previously been employed (Issberner and Sillar, 2007; Dubuc et al., 2008; McLean et al., 2008; Kyriakatos et al., 2011), while retaining the capacity to study them directly from the subcellular to systems level.

Bath-applied NMDA leads to a large increase in baseline $\mathrm{Ca}^{2+}{ }_{\mathrm{i}}$ while $\mathrm{Ca}^{2+}$ oscillations are synchronized throughout the dendrites of a single neuron (Bacskai et al., 1995; Viana di Prisco and Alford, 2004). In this context, all NMDARs will 
become active and are independent of presynaptic release of glutamate. Under these conditions, the precise relationship between activated routes of $\mathrm{Ca}^{2+}$ entry, whether NMDARs or VGCCs, may become obscured. This may allow $\mathrm{K}_{\mathrm{Ca}} 2$ channels to couple to $\mathrm{Ca}^{2+}$ microdomains as opposed to nanodomains implied by their physiological BAPTA sensitivity. Indeed, in VHNs dialyzed with EGTA, oscillation plateau progressively lengthen immediately following whole-cell access, on a time course equivalent to the diffusion of dyes to the most distal dendrites (Alpert and Alford, 2013). This may be interpreted as a progressive increase in EGTA-mediated $\mathrm{Ca}^{2+}$ buffering into the distal dendrites where $\mathrm{Ca}^{2+}$ oscillations are largest (Viana di Prisco and Alford, 2004), preventing some $\mathrm{Ca}^{2+}$ from binding $\mathrm{K}_{\mathrm{Ca}} 2$ channels to cause the repolarization (Alpert and Alford, 2013). This effect suggests that $\mathrm{Ca}^{2+}$ diffusing greater distances from its site of entry can, under certain circumstances, activate $\mathrm{K}_{\mathrm{Ca}} 2$ channels, which then contribute to the repolarization. Nevertheless, even under these non-physiological conditions of bath applied NMDA, cells dialyzed with BAPTA displayed immediate, severely impaired repolarization (Alpert and Alford, 2013).

The ability of NMDAR-induced $\mathrm{Ca}^{2+}$ entry to bind $\mathrm{K}_{\mathrm{Ca}} 2$ channels in $\mathrm{Ca}^{2+}$ microdomains may be an artifact of bathapplied NMDA and the robust increase in intracellular $\mathrm{Ca}^{2+}$, which may also cause $\mathrm{Ca}^{2+}$-induced $\mathrm{Ca}^{2+}$ release from internal stores. However, it was recently demonstrated that this $\mathrm{K}_{\mathrm{Ca}} 2$ channel conductance is physiologically activated by synaptically driven NMDAR-mediated $\mathrm{Ca}^{2+}$ entry (Alpert and Alford, 2013) and is vital for the proper functioning of the network during brain-evoked locomotion (Nanou et al., 2013). If the spatially and temporally precise synaptic activation of glutamate receptors during locomotion is sensitive to blockade of $\mathrm{K}_{\mathrm{Ca}} 2$ channels, then it should follow that there is complementary patterning dendritic $\mathrm{Ca}^{2+}$ entry which drives the activation of $\mathrm{K}_{\mathrm{Ca}} 2$ channels important for rhythm generation. However, we know very little about the spatiotemporal pattern of dendrite activation during behavior and how synaptic input is integrated in real time to impact cell output.

Several recent advances have made it possible to begin to assess how dendrites integrate incoming synaptic information within an active, behaving network. Dendritic spatiotemporal $\mathrm{Ca}^{2+}$ dynamics in active networks are crucial to understanding how physiological patterns of synaptic input are integrated in real time to shape the cellular output and have only recently been investigated. With new advances in genetically encoded $\mathrm{Ca}^{2+}$ indicators (Muto et al., 2011) and in vivo 2-photon microscopy, it is now becoming possible to "watch dendrites in action" and correlate their activity to sensory input and behavioral output (Dombeck et al., 2010; Xu et al., 2012; Smith et al., 2013b; Grienberger et al., 2014). However, particularly in the lamprey model system, but presumably in other systems like zebrafish, there is a distinct advantage in imaging dendritic behavior-the activity of spinal motoneuron and interneuronal dendrites and the subsequent electrical output of individual cells can be precisely correlated to the real time network output, whose role in generating behavior is well characterized and directly measureable. Such multilevel analyses will undoubtedly enhance our understanding of how nervous systems generate behavior from subcellular to systems level with unprecedented detail.

\section{REFERENCES}

Abalo, X. M., Villar-Cheda, B., Meléndez-Ferro, M., Pérez-Costas, E., Anadón, R., and Rodicio, M. C. (2007). Development of the serotonergic system in the central nervous system of the sea lamprey. J. Chem. Neuroanat. 34, 29-46. doi: 10.1016/j.jchemneu.2007.03.010

Akita, T., and Kuba, K. (2000). Functional triads consisting of ryanodine receptors, $\mathrm{Ca}(2+)$ channels and $\mathrm{Ca}(2+)$-activated $\mathrm{K}(+)$ channels in bullfrog sympathetic neurons. Plastic modulation of action potential. J. Gen. Physiol. 116, 697-720. doi: 10.1085/jgp.116.5.697

Alford, S., Frenguelli, B. G., Schofield, J. G., and Collingridge, G. L. (1993). Characterization of $\mathrm{Ca} 2+$ signals induced in hippocampal CA1 neurones by the synaptic activation of NMDA receptors. J. Physiol. 469, 693-716.

Alford, S., and Grillner, S. (1990). CNQX and DNQX block non-NMDA synaptic transmission but not NMDA-evoked locomotion in lamprey spinal cord. Brain Res. 506, 297-302. doi: 10.1016/0006-8993(90)91266-j

Alford, S., Schwartz, E., and Viana di Prisco, G. (2003). The pharmacology of vertebrate spinal central pattern generators. Neuroscientist 9, 217-228. doi: 10 . $1177 / 1073858403009003014$

Alford, S., and Williams, T. L. (1989). Endogenous activation of glycine and NMDA receptors in lamprey spinal cord during fictive locomotion. J. Neurosci. 9, 27922800.

Alpert, M. H., and Alford, S. (2013). Synaptic NMDA receptor-dependent $\mathrm{Ca}^{2+}$ entry drives membrane potential and $\mathrm{Ca}^{2+}$ oscillations in spinal ventral horn neurons. PLoS One 8:e63154. doi: 10.1371/journal.pone.0063154

Anderson, C. T., Sheets, P. L., Kiritani, T., and Shepherd, G. M. G. (2010). Sublayerspecific microcircuits of corticospinal and corticostriatal neurons in motor cortex. Nat. Neurosci. 13, 739-744. doi: 10.1038/nn.2538

Antri, M., Auclair, F., Albrecht, J., Djeudjang, N., and Dubuc, R. (2008). Serotoninergic modulation of sensory transmission to brainstem reticulospinal cells. Eur. J. Neurosci. 28, 655-667. doi: 10.1111/j.1460-9568.2008.06368.x

Ascher, P., and Nowak, L. (1988). The role of divalent cations in the N-methyl-Daspartate responses of mouse central neurones in culture. J. Physiol. 399, 247266.

Augustinaite, S., Kuhn, B., Helm, P. J., and Heggelund, P. (2014). NMDA spike/plateau potentials in dendrites of thalamocortical neurons. J. Neurosci. 34, 10892-10905. doi: 10.1523/JNEUROSCI.1205-13.2014

Augustine, G. J., Santamaria, F., and Tanaka, K. (2003). Local calcium signaling in neurons. Neuron 40, 331-346. doi: 10.1016/s0896-6273(03) 00639-1

Bacskai, B. J., Wallén, P., Lev-Ram, V., Grillner, S., and Tsien, R. Y. (1995). Activity-related calcium dynamics in lamprey motoneurons as revealed by video-rate confocal microscopy. Neuron 14, 19-28. doi: 10.1016/0896-6273(95) 90237-6

Ballesteros-Merino, C., Lin, M., Wu, W. W., Ferrandiz-Huertas, C., Cabañero, M. J., Watanabe, M., et al. (2012). Developmental profile of SK2 channel expression and function in CA1 neurons. Hippocampus 22, 1467-1480. doi: 10.1002/hipo. 20986

Barbeau, H., and Rossignol, S. (1990). The effects of serotonergic drugs on the locomotor pattern and on cutaneous reflexes of the adult chronic spinal cat. Brain Res. 514, 55-67. doi: 10.1016/0006-8993(90)90435-e

Barreiro-Iglesias, A., Villar-Cerviño, V., Anadón, R., and Rodicio, M. C. (2008). Development and organization of the descending serotonergic brainstem-spinal projections in the sea lamprey. J. Chem. Neuroanat. 36, 77-84. doi: 10.1016/j. jchemneu.2008.06.001

Berridge, M. J. (2006). Calcium microdomains: organization and function. Cell Calcium 40, 405-412. doi: 10.1016/j.ceca.2006.09.002

Blackmer, T., Larsen, E. C., Bartleson, C., Kowalchyk, J. A., Yoon, E.-J., Preininger, A. M., et al. (2005). G protein betagamma directly regulates SNARE protein fusion machinery for secretory granule exocytosis. Nat. Neurosci. 8, 421-425. doi: 10.1038/nn1423

Blackmer, T., Larsen, E. C., Takahashi, M., Martin, T. F., Alford, S., and Hamm, H. E. (2001). G protein betagamma subunit-mediated presynaptic inhibition: regulation of exocytotic fusion downstream of Ca2+ entry. Science 292, 293 297. doi: $10.1126 /$ science. 1058803 
Bloodgood, B. L., and Sabatini, B. L. (2007). Nonlinear regulation of unitary synaptic signals by $\mathrm{CaV}(2.3)$ voltage-sensitive calcium channels located in dendritic spines. Neuron 53, 249-260. doi: 10.1016/j.neuron.2006. 12.017

Bollmann, J. H., and Engert, F. (2009). Subcellular topography of visually driven dendritic activity in the vertebrate visual system. Neuron 61, 895-905. doi: 10. 1016/j.neuron.2009.01.018

Bond, C. T., Herson, P. S., Strassmaier, T., Hammond, R., Stackman, R., Maylie, J., et al. (2004). Small conductance Ca2+-activated K+ channel knock-out mice reveal the identity of calcium-dependent afterhyperpolarization currents. $J$. Neurosci. 24, 5301-5306. doi: 10.1523/jneurosci.0182-04.2004

Branco, T., Clark, B. A., and Häusser, M. (2010). Dendritic discrimination of temporal input sequences in cortical neurons. Science 329, 1671-1675. doi: 10. 1126/science. 1189664

Branco, T., and Häusser, M. (2010). The single dendritic branch as a fundamental functional unit in the nervous system. Curr. Opin. Neurobiol. 20, 494-502. doi: 10.1016/j.conb.2010.07.009

Brierley, D. J., Blanc, E., Reddy, O. V., VijayRaghavan, K., and Williams, D. W. (2009). Dendritic targeting in the leg neuropil of Drosophila: the role of midline signalling molecules in generating a myotopic map. PLoS Biol. 7:e1000199. doi: 10.1371/journal.pbio.1000199

Brodin, L., and Grillner, S. (1985). The role of putative excitatory amino acid neurotransmitters in the initiation of locomotion in the lamprey spinal cord. I. The effects of excitatory amino acid antagonists. Brain Res. 360, 139-148. doi: 10.1016/0006-8993(85)91229-6

Brodin, L., Grillner, S., Dubuc, R., Ohta, Y., Kasicki, S., and Hökfelt, T. (1988). Reticulospinal neurons in lamprey: transmitters, synaptic interactions and their role during locomotion. Arch. Ital. Biol. 126, 317-345.

Brodin, L., Grillner, S., and Rovainen, C. M. (1985). N-Methyl-D-Aspartate (NMDA), kainate and quisqualate receptors and the generation of fictive locomotion in the lamprey spinal cord. Brain Res. 325, 302-306. doi: 10.1016/00068993(85)90328-2

Buchanan, J. T. (1982). Identification of interneurons with contralateral, caudal axons in the lamprey spinal cord: synaptic interactions and morphology. $J$. Neurophysiol. 47, 961-975.

Buchanan, J. T. (1993). Electrophysiological properties of identified classes of lamprey spinal neurons. J. Neurophysiol. 70, 2313-2325.

Buchanan, J. T. (2001). Contributions of identifiable neurons and neuron classes to lamprey vertebrate neurobiology. Prog. Neurobiol. 63, 441-466. doi: 10. 1016/s0301-0082(00)00050-2

Buchanan, J. T., Brodin, L., Dale, N., and Grillner, S. (1987). Reticulospinal neurones activate excitatory amino acid receptors. Brain Res. 408, 321-325. doi: 10.1016/0006-8993(87)90397-0

Buchanan, J. T., and Cohen, A. H. (1982). Activities of identified interneurons, motoneurons and muscle fibers during fictive swimming in the lamprey and effects of reticulospinal and dorsal cell stimulation. J. Neurophysiol. 47, 948-960. Available online at: http://jn.physiology.org/content/47/5/948.abstract.

Buchanan, J. T., and Grillner, S. (1987). Newly identified 'glutamate interneurons' and their role in locomotion in the lamprey spinal cord. Science 236, 312-314. doi: 10.1126/science.3563512

Buchanan, J. T., and Grillner, S. (1991). 5-Hydroxytryptamine depresses reticulospinal excitatory postsynaptic potentials in motoneurons of the lamprey. Neurosci. Lett. 122, 71-74. doi: 10.1016/0304-3940(91)90196-z

Buchanan, J. T., Grillner, S., Cullheim, S., and Risling, M. (1989). Identification of excitatory interneurons contributing to generation of locomotion in lamprey: structure, pharmacology and function. J. Neurophysiol. 62, 59-69.

Buzsáki, G., and Draguhn, A. (2004). Neuronal oscillations in cortical networks. Science 304, 1926-1929. doi: 10.1126/science.1099745

Buzsáki, G., and Moser, E. I. (2013). Memory, navigation and theta rhythm in the hippocampal-entorhinal system. Nat. Neurosci. 16, 130-138. doi: 10.1038/nn. 3304

Cai, X., Liang, C. W., Muralidharan, S., Kao, J. P. Y., Tang, C.-M., and Thompson, S. M. (2004). Unique roles of SK and Kv4.2 potassium channels in dendritic integration. Neuron 44, 351-364. doi: 10.1016/j.neuron.2004. 09.026

Cangiano, L., Wallén, P., and Grillner, S. (2002). Role of apamin-sensitive k(ca) channels for reticulospinal synaptic transmission to motoneuron and for the afterhyperpolarization. J. Neurophysiol. 88, 289-299.
Cazalets, J. R., Sqalli-Houssaini, Y., and Clarac, F. (1992). Activation of the central pattern generators for locomotion by serotonin and excitatory amino acids in neonatal rat. J. Physiol. 455, 187-204.

Chau, C., Giroux, N., Barbeau, H., Jordan, L., and Rossignol, S. (2002). Effects of intrathecal glutamatergic drugs on locomotion I. NMDA in short-term spinal cats. J. Neurophysiol. 88, 3032-3045. doi: 10.1152/jn.00138. 2002

Chen, X., Leischner, U., Rochefort, N. L., Nelken, I., and Konnerth, A. (2011). Functional mapping of single spines in cortical neurons in vivo. Nature 475, 501-505. doi: 10.1038/nature10193

Choi, S., Klingauf, J., and Tsien, R. W. (2000). Postfusional regulation of cleft glutamate concentration during LTP at 'silent synapses'. Nat. Neurosci. 3, 330336. doi: 10.1038/73895

Cohen, A. H., and Wallén, P. (1980). The neuronal correlate of locomotion in fish. Exp. Brain Res. 41, 11-18. doi: 10.1007/bf00236674

Contreras, D., and Steriade, M. (1995). Cellular basis of EEG slow rhythms: a study of dynamic corticothalamic relationships. J. Neurosci. 15, 604-622.

Dale, N., and Roberts, A. (1984). Excitatory amino acid receptors in Xenopus embryo spinal cord and their role in the activation of swimming. J. Physiol. 348, 527-543.

Dale, N., and Roberts, A. (1985). Dual-component amino-acid-mediated synaptic potentials: excitatory drive for swimming in Xenopus embryos. J. Physiol. 363, 35-59.

Deister, C. A., Teagarden, M. A., Wilson, C. J., and Paladini, C. A. (2009). An intrinsic neuronal oscillator underlies dopaminergic neuron bursting. J. Neurosci. 29, 15888-15897. doi: 10.1523/JNEUROSCI.4053-09.2009

Delvolvé, I., Bem, T., and Cabelguen, J. M. (1997). Epaxial and limb muscle activity during swimming and terrestrial stepping in the adult newt, Pleurodeles waltl. J. Neurophysiol. 78, 638-650.

Díaz-Ríos, M., Dombeck, D. A., Webb, W. W., and Harris-Warrick, R. M. (2007). Serotonin modulates dendritic calcium influx in commissural interneurons in the mouse spinal locomotor network. J. Neurophysiol. 98, 2157-2167. doi: 10. 1152/jn.00430.2007

Dombeck, D. A., Harvey, C. D., Tian, L., Looger, L. L., and Tank, D. W. (2010). Functional imaging of hippocampal place cells at cellular resolution during virtual navigation. Nat. Neurosci. 13, 1433-1440. doi: 10.1038/nn.2648

Douglas, J. R., Noga, B. R., Dai, X., and Jordan, L. M. (1993). The effects of intrathecal administration of excitatory amino acid agonists and antagonists on the initiation of locomotion in the adult cat. J. Neurosci. 13, 990-1000.

Dubuc, R., Brocard, F., Antri, M., Fénelon, K., Gariépy, J.-F., Smetana, R., et al. (2008). Initiation of locomotion in lampreys. Brain Res. Rev. 57, 172-182. doi: 10.1016/j.brainresrev.2007.07.016

Durstewitz, D., Seamans, J. K., and Sejnowski, T. J. (2000). Neurocomputational models of working memory. Nat. Neurosci. 3(Suppl.), 1184-1191. doi: 10. $1038 / 81460$

El Manira, A., and Bussières, N. (1997). Calcium channel subtypes in lamprey sensory and motor neurons. J. Neurophysiol. 78, 1334-1340.

El Manira, A., Tegnér, J., and Grillner, S. (1994). Calcium-dependent potassium channels play a critical role for burst termination in the locomotor network in lamprey. J. Neurophysiol. 72, 1852-1861.

Enoki, R., Hu, Y.-L., Hamilton, D., and Fine, A. (2009). Expression of long-term plasticity at individual synapses in hippocampus is graded, bidirectional and mainly presynaptic: optical quantal analysis. Neuron 62, 242-253. doi: 10.1016/j. neuron.2009.02.026

Ericsson, J., Stephenson-Jones, M., Pérez-Fernández, J., Robertson, B., Silberberg, G., and Grillner, S. (2013). Dopamine differentially modulates the excitability of striatal neurons of the direct and indirect pathways in lamprey. J. Neurosci. 33, 8045-8054. doi: 10.1523/JNEUROSCI.5881-12.2013

Faber, E. S. L. (2010). Functional interplay between NMDA receptors, SK channels and voltage-gated $\mathrm{Ca} 2+$ channels regulates synaptic excitability in the medial prefrontal cortex. J. Physiol. 588, 1281-1292. doi: 10.1113/jphysiol.2009.185645

Faber, E. S. L., Delaney, A. J., and Sah, P. (2005). SK channels regulate excitatory synaptic transmission and plasticity in the lateral amygdala. Nat. Neurosci. 8, 635-641. doi: 10.1038/nn1450

Faber, E. S. L., and Sah, P. (2002). Physiological role of calcium-activated potassium currents in the rat lateral amygdala. J. Neurosci. 22, 1618-1628.

Fakler, B., and Adelman, J. P. (2008). Control of K(Ca) channels by calcium nano/microdomains. Neuron 59, 873-881. doi: 10.1016/j.neuron.2008.09.001 
Field, E. C., and Stein, P. S. (1997). Spinal cord coordination of hindlimb movements in the turtle: intralimb temporal relationships during scratching and swimming. J. Neurophysiol. 78, 1394-1403.

Flatman, J. A., Schwindt, P. C., and Crill, W. E. (1986). The induction and modification of voltage-sensitive responses in cat neocortical nuerons by $\mathrm{N}$ methyl-D-aspartate. Brain Res. 363, 62-77. doi: 10.1016/0006-8993(86)90659-1

Forssberg, H., Grillner, S., Halbertsma, J., and Rossignol, S. (1980). The locomotion of the low spinal cat. II. Interlimb coordination. Acta Physiol. Scand. 108, 283 295. doi: 10.1111/j.1748-1716.1980.tb06534.x

Frenguelli, B. G., Potier, B., Slater, N. T., Alford, S., and Collingridge, G. L. (1993). Metabotropic glutamate receptors and calcium signalling in dendrites of hippocampal CA1 neurones. Neuropharmacology 32, 1229-1237. doi: 10. 1016/0028-3908(93)90017-w

Gabriel, J. P., Mahmood, R., Kyriakatos, A., Söll, I., Hauptmann, G., Calabrese, R. L., et al. (2009). Serotonergic modulation of locomotion in zebrafish: endogenous release and synaptic mechanisms. J. Neurosci. 29, 10387-10395. doi: 10. 1523/JNEUROSCI.1978-09.2009

Gao, Z., van Beugen, B. J., and De Zeeuw, C. I. (2012). Distributed synergistic plasticity and cerebellar learning. Nat. Rev. Neurosci. 13, 619-635. doi: 10. 1038/nrn3391

Gerachshenko, T., Schwartz, E., Bleckert, A., Photowala, H., Seymour, A., and Alford, S. (2009). Presynaptic G-protein-coupled receptors dynamically modify vesicle fusion, synaptic cleft glutamate concentrations and motor behavior. J. Neurosci. 29, 10221-10233. doi: 10.1523/JNEUROSCI.1404-09.2009

Goulding, M. (2009). Circuits controlling vertebrate locomotion: moving in a new direction. Nat. Rev. Neurosci. 10, 507-518. doi: 10.1038/nrn2608

Grienberger, C., Chen, X., and Konnerth, A. (2014). NMDA receptor-dependent multidendrite $\mathrm{Ca} 2+$ spikes required for hippocampal burst firing in vivo. Neuron 81, 1274-1281. doi: 10.1016/j.neuron.2014.01.014

Grillner, S. (2003). The motor infrastructure: from ion channels to neuronal networks. Nat. Rev. Neurosci. 4, 573-586. doi: 10.1038/nrn1137

Grillner, S. (2006). Biological pattern generation: the cellular and computational logic of networks in motion. Neuron 52, 751-766. doi: 10.1016/j.neuron.2006. 11.008

Grillner, S., Cangiano, L., Hu, G., Thompson, R., Hill, R., and Wallén, P. (2000). The intrinsic function of a motor system-from ion channels to networks and behavior. Brain Res. 886, 224-236. doi: 10.1016/s0006-8993(00) 03088-2

Grillner, S., Markram, H., De Schutter, E., Silberberg, G., and LeBeau, F. E. N. (2005). Microcircuits in action-from CPGs to neocortex. Trends Neurosci. 28, 525-533. doi: 10.1016/j.tins.2005.08.003

Grillner, S., McClellan, A., Sigvardt, K., Wallén, P., and Wilén, M. (1981). Activation of NMDA-receptors elicits "fictive locomotion" in lamprey spinal cord in vitro. Acta Physiol. Scand. 113, 549-551. doi: 10.1111/j.1748-1716.1981.tb06937.x

Grillner, S., Robertson, B., and Stephenson-Jones, M. (2013). The evolutionary origin of the vertebrate basal ganglia and its role in action-selection. J. Physiol. 591, 5425-5431. doi: 10.1113/jphysiol.2012.246660

Grillner, S., and Wallén, P. (1980). Does the central pattern generation for locomotion in lamprey depend on glycine inhibition? Acta Physiol. Scand. 110, 103-105. doi: 10.1111/j.1748-1716.1980.tb06637.x

Grillner, S., and Wallén, P. (1985). The ionic mechanisms underlying N-methyl-Daspartate receptor-induced, tetrodotoxin-resistant membrane potential oscillations in lamprey neurons active during locomotion. Neurosci. Lett. 60, 289-294. doi: 10.1016/0304-3940(85)90592-0

Grillner, S., Wallén, P., Hill, R., Cangiano, L., and El Manira, A. (2001). Ion channels of importance for the locomotor pattern generation in the lamprey brainstem-spinal cord. J. Physiol. 533, 23-30. doi: 10.1111/j.1469-7793.2001. 0023b.x

Grillner, S., Wallén, P., Saitoh, K., Kozlov, A., and Robertson, B. (2008). Neural bases of goal-directed locomotion in vertebrates-an overview. Brain Res. Rev. 57, 2-12. doi: 10.1016/j.brainresrev.2007.06.027

Gu, N., Hu, H., Vervaeke, K., and Storm, J. F. (2008). SK (KCa2) channels do not control somatic excitability in CA1 pyramidal neurons but can be activated by dendritic excitatory synapses and regulate their impact. J. Neurophysiol. 100, 2589-2604. doi: 10.1152/jn.90433.2008

Guertin, P. A., and Hounsgaard, J. (1998). NMDA-Induced intrinsic voltage oscillations depend on L-type calcium channels in spinal motoneurons of adult turtles. J. Neurophysiol. 80, 3380-3382.
Hammond, R. S., Bond, C. T., Strassmaier, T., Ngo-Anh, T. J., Adelman, J. P., Maylie, J., et al. (2006). Small-conductance Ca2+-activated K+ channel type 2 (SK2) modulates hippocampal learning, memory and synaptic plasticity. J. Neurosci. 26, 1844-1853. doi: 10.1523/jneurosci.4106-05.2006

Han, P., Nakanishi, S. T., Tran, M. A., and Whelan, P. J. (2007). Dopaminergic modulation of spinal neuronal excitability. J. Neurosci. 27, 13192-13204. doi: 10. 1523/jneurosci.1279-07.2007

Harris-Warrick, R. M. (2002). Voltage-sensitive ion channels in rhythmic motor systems. Curr. Opin. Neurobiol. 12, 646-651. doi: 10.1016/s09594388(02)00377-x

Harris-Warrick, R. M., and Cohen, A. H. (1985). Serotonin modulates the central pattern generator for locomotion in the isolated lamprey spinal cord. J. Exp. Biol. $116,27-46$.

Harvey-Girard, E., and Maler, L. (2013). Dendritic SK channels convert NMDA-Rdependent LTD to burst timing-dependent plasticity. J. Neurophysiol. 110, 26892703. doi: 10.1152/jn.00506.2013

Häusser, M., and Mel, B. (2003). Dendrites: bug or feature? Curr. Opin. Neurobiol. 13, 372-383. doi: 10.1016/s0959-4388(03)00075-8

Hernandez, P., Elbert, K., and Droge, M. H. (1991). Spontaneous and NMDA evoked motor rhythms in the neonatal mouse spinal cord: an in vitro study with comparisons to in situ activity. Exp. Brain Res. 85, 66-74. doi: 10. 1007/bf00229987

Hill, R. H., Brodin, L., and Grillner, S. (1989). Activation of N-methyl-D-aspartate (NMDA) receptors augments repolarizing responses in lamprey spinal neurons. Brain Res. 499, 388-392. doi: 10.1016/0006-8993(89)90790-7

Hill, R., Matsushima, T., Schotland, J., and Grillner, S. (1992). Apamin blocks the slow AHP in lamprey and delays termination of locomotor bursts. Neuroreport 3, 943-945. doi: 10.1097/00001756-199210000-00032

Hill, R. H., Svensson, E., Dewael, Y., and Grillner, S. (2003). 5-HT inhibits N-type but not L-type $\mathrm{Ca}(2+)$ channels via 5-HT1A receptors in lamprey spinal neurons. Eur. J. Neurosci. 18, 2919-2924. doi: 10.1111/j.1460-9568.2003. 03051.x

Hochman, S., Jordan, L. M., and Schmidt, B. J. (1994). TTX-resistant NMDA receptor-mediated voltage oscillations in mammalian lumbar motoneurons. $J$. Neurophysiol. 72, 2559-2562.

Hsiao, C.-F., Wu, N., Levine, M. S., and Chandler, S. H. (2002). Development and serotonergic modulation of NMDA bursting in rat trigeminal motoneurons. $J$. Neurophysiol. 87, 1318-1328.

Isope, P., Hildebrand, M. E., and Snutch, T. P. (2012). Contributions of Ttype voltage-gated calcium channels to postsynaptic calcium signaling within Purkinje neurons. Cerebellum 11, 651-665. doi: 10.1007/s12311-010-0195-4

Issberner, J. P., and Sillar, K. T. (2007). The contribution of the NMDA receptor glycine site to rhythm generation during fictive swimming in Xenopus laevis tadpoles. Eur. J. Neurosci. 26, 2556-2564. doi: 10.1111/j.1460-9568.2007. 05892.x

Ito, M. (2006). Cerebellar circuitry as a neuronal machine. Prog. Neurobiol. 78, 272 303. doi: 10.1016/j.pneurobio.2006.02.006

Jarsky, T., Roxin, A., Kath, W. L., and Spruston, N. (2005). Conditional dendritic spike propagation following distal synaptic activation of hippocampal CA1 pyramidal neurons. Nat. Neurosci. 8, 1667-1676. doi: 10.1038/nn1599

Jia, H., Rochefort, N. L., Chen, X., and Konnerth, A. (2010). Dendritic organization of sensory input to cortical neurons in vivo. Nature 464, 1307-1312. doi: 10. 1038 /nature 08947

Johnson, S. W., Seutin, V., and North, R. A. (1992). Burst firing in dopamine neurons induced by N-methyl-D-aspartate: role of electrogenic sodium pump. Science 258, 665-667. doi: 10.1126/science.1329209

Jones, R. S., Pedisich, M., Carroll, R. C., and Nawy, S. (2014). Spatial organization of AMPAR subtypes in ON RGCs. J. Neurosci. 34, 656-661. doi: 10. 1523/JNEUROSCI.1140-13.2014

Jones, S. L., and Stuart, G. J. (2013). Different calcium sources control somatic versus dendritic SK channel activation during action potentials. J. Neurosci. 33, 19396-19405. doi: 10.1523/JNEUROSCI.2073-13.2013

Kahn, J. A., and Roberts, A. (1978). The central nervous generation of the swimming rhythm in an amphibian embryo [proceedings]. J. Physiol. 277, 20P-21P.

Kasicki, S., Grillner, S., Ohta, Y., Dubuc, R., and Brodin, L. (1989). Phasic modulation of reticulospinal neurones during fictive locomotion and other types of spinal motor activity in lamprey. Brain Res. 484, 203-216. doi: 10.1016/00068993(89)90363-6 
Kawai, T., and Watanabe, M. (1989). Effects of ryanodine on the spike afterhyperpolarization in sympathetic neurones of the rat superior cervical ganglion. Pflugers Arch. 413, 470-475. doi: 10.1007/bf00594175

Kettunen, P., Krieger, P., Hess, D., and El Manira, A. (2002). Signaling mechanisms of metabotropic glutamate receptor 5 subtype and its endogenous role in a locomotor network. J. Neurosci. 22, 1868-1873.

Kim, Y. I., and Chandler, S. H. (1995). NMDA-induced burst discharge in guinea pig trigeminal motoneurons in vitro. J. Neurophysiol. 74, 334-346.

Kishore, S., and Fetcho, J. R. (2013). Homeostatic regulation of dendritic dynamics in a motor map in vivo. Nat. Commun. 4:2086. doi: 10.1038/ncomms3086

Kleindienst, T., Winnubst, J., Roth-Alpermann, C., Bonhoeffer, T., and Lohmann, C. (2011). Activity-dependent clustering of functional synaptic inputs on developing hippocampal dendrites. Neuron 72, 1012-1024. doi: 10.1016/j.neuron. 2011.10.015

Koshiya, N., and Smith, J. C. (1999). Neuronal pacemaker for breathing visualized in vitro. Nature 400, 360-363. doi: 10.1038/22540

Kosugi, M., Kato, G., Lukashov, S., Pendse, G., Puskar, Z., Kozsurek, M., et al. (2013). Subpopulation-specific patterns of intrinsic connectivity in mouse superficial dorsal horn as revealed by laser scanning photostimulation. J. Physiol. 591, 1935-1949. doi: 10.1113/jphysiol.2012.244210

Kozlov, A., Kotaleski, J. H., Aurell, E., Grillner, S., and Lansner, A. (2001). Modeling of substance P and 5-HT induced synaptic plasticity in the lamprey spinal CPG: consequences for network pattern generation. J. Comput. Neurosci. 11, 183-200. doi: 10.1023/A:1012806018730

Krieger, P., Hellgren-Kotaleski, J., Kettunen, P., and El Manira, A. J. (2000). Interaction between metabotropic and ionotropic glutamate receptors regulates neuronal network activity. J. Neurosci. 20, 5382-5391.

Kudo, N., and Yamada, T. (1987). N-methyl-D,L-aspartate-induced locomotor activity in a spinal cord-hindlimb muscles preparation of the newborn rat studied in vitro. Neurosci. Lett. 75, 43-48. doi: 10.1016/0304-3940(87)90072-3

Kyriakatos, A., Mahmood, R., Ausborn, J., Porres, C. P., Büschges, A., and El Manira, A. (2011). Initiation of locomotion in adult zebrafish. J. Neurosci. 31, 8422-8431. doi: 10.1523/JNEUROSCI.1012-11.2011

Landgraf, M., Jeffrey, V., Fujioka, M., Jaynes, J. B., and Bate, M. (2003). Embryonic origins of a motor system: motor dendrites form a myotopic map in Drosophila. PLoS Biol. 1:E41. doi: 10.1371/journal.pbio.0000041

Larkum, M. E., Nevian, T., Sandler, M., Polsky, A., and Schiller, J. (2009). Synaptic integration in tuft dendrites of layer 5 pyramidal neurons: a new unifying principle. Science 325, 756-760. doi: 10.1126/science.1171958

Larkum, M. E., Watanabe, S., Nakamura, T., Lasser-Ross, N., and Ross, W. N. (2003). Synaptically activated Ca2+ waves in layer $2 / 3$ and layer 5 rat neocortical pyramidal neurons. J. Physiol. 549, 471-488. doi: 10.1113/jphysiol.2002.037614

Larkum, M. E., Zhu, J. J., and Sakmann, B. (1999). A new cellular mechanism for coupling inputs arriving at different cortical layers. Nature 398, 338-341. doi: 10. 1038/18686

Leresche, N., Lightowler, S., Soltesz, I., Jassik-Gerschenfeld, D., and Crunelli, V. (1991). Low-frequency oscillatory activities intrinsic to rat and cat thalamocortical cells. J. Physiol. 441, 155-174.

Li, X., and Bennett, D. J. (2007). Apamin-sensitive calcium-activated potassium currents (SK) are activated by persistent calcium currents in rat motoneurons. J. Neurophysiol. 97, 3314-3330. doi: 10.1152/jn.01068.2006

Li, W.-C., Cooke, T., Sautois, B., Soffe, S. R., Borisyuk, R., and Roberts, A. (2007). Axon and dendrite geography predict the specificity of synaptic connections in a functioning spinal cord network. Neural Dev. 2:17. doi: 10.1186/1749-8104-2-17

Li, W.-C., Roberts, A., and Soffe, S. R. (2010). Specific brainstem neurons switch each other into pacemaker mode to drive movement by activating NMDA receptors. J. Neurosci. 30, 16609-16620. doi: 10.1523/JNEUROSCI.3695-10. 2010

Lin, M. T., Luján, R., Watanabe, M., Adelman, J. P., and Maylie, J. (2008). SK2 channel plasticity contributes to LTP at Schaffer collateral-CA1 synapses. Nat. Neurosci. 11, 170-177. doi: 10.1038/nn2041

Lisman, J. E., Fellous, J. M., and Wang, X. J. (1998). A role for NMDA-receptor channels in working memory. Nat. Neurosci. 1, 273-275. doi: 10.1038/1086

Llinás, R. (1988). The intrinsic electrophysiological properties of mammalian neurons: insights into central nervous system function. Science 242, 1654-1664. doi: 10.1126/science.3059497

Llinás, R., and Yarom, Y. (1981). Properties and distribution of ionic conductances generating electroresponsiveness of mammalian inferior olivary neurones in vitro. J. Physiol. 315, 569-584.
Losonczy, A., and Magee, J. C. (2006). Integrative properties of radial oblique dendrites in hippocampal CA1 pyramidal neurons. Neuron 50, 291-307. doi: 10. 1016/j.neuron.2006.03.016

MacDermott, A. B., Mayer, M. L., Westbrook, G. L., Smith, S. J., and Barker, J. L. (1986). NMDA-receptor activation increases cytoplasmic calcium concentration in cultured spinal cord neurones. Nature 321, 519-522. doi: 10.1038/321519a0

Maciaszek, J. L., Soh, H., Walikonis, R. S., Tzingounis, A. V., and Lykotrafitis, G. (2012). Topography of native SK channels revealed by force nanoscopy in living neurons. J. Neurosci. 32, 11435-11440. doi: 10.1523/JNEUROSCI.1785-12. 2012

Maher, B. J., and Westbrook, G. L. (2005). SK channel regulation of dendritic excitability and dendrodendritic inhibition in the olfactory bulb. J. Neurophysiol. 94, 3743-3750. doi: 10.1152/jn.00797.2005

Major, G., Polsky, A., Denk, W., Schiller, J., and Tank, D. W. (2008). Spatiotemporally graded NMDA spike/plateau potentials in basal dendrites of neocortical pyramidal neurons. J. Neurophysiol. 99, 2584-2601. doi: 10.1152/jn.00011. 2008

Makino, H., and Malinow, R. (2011). Compartmentalized versus global synaptic plasticity on dendrites controlled by experience. Neuron 72, 1001-1011. doi: 10 . 1016/j.neuron.2011.09.036

Marder, E., and Bucher, D. (2007). Understanding circuit dynamics using the stomatogastric nervous system of lobsters and crabs. Annu. Rev. Physiol. 69, 291316. doi: 10.1146/annurev.physiol.69.031905.161516

Marrion, N. V., and Tavalin, S. J. (1998). Selective activation of Ca2+-activated K+ channels by co-localized Ca2+ channels in hippocampal neurons. Nature 395, 900-905. doi: 10.1038/27674

Masino, M. A., Abbinanti, M. D., Eian, J., and Harris-Warrick, R. M. (2012). TTX-resistant NMDA receptor-mediated membrane potential oscillations in neonatal mouse Hb9 interneurons. PLoS One 7:e47940. doi: 10.1371/journal. pone. 0047940

Masino, M. A., and Fetcho, J. R. (2005). Fictive swimming motor patterns in wild type and mutant larval zebrafish. J. Neurophysiol. 93, 3177-3188. doi: 10 . 1152/jn.01248.2004

Matsuzaki, M., Honkura, N., Ellis-Davies, G. C. R., and Kasai, H. (2004). Structural basis of long-term potentiation in single dendritic spines. Nature 429, 761-766. doi: $10.1038 /$ nature02617

Mauss, A., Tripodi, M., Evers, J. F., and Landgraf, M. (2009). Midline signalling systems direct the formation of a neural map by dendritic targeting in the Drosophila motor system. PLoS Biol. 7:e1000200. doi: 10.1371/journal.pbio. 1000200

McLean, D. L., Fan, J., Higashijima, S.-I., Hale, M. E., and Fetcho, J. R. (2007). A topographic map of recruitment in spinal cord. Nature 446, 71-75. doi: 10. 1038 /nature 05588

McLean, D. L., Masino, M. A., Koh, I. Y., Lindquist, W. B., and Fetcho, J. R. (2008). Continuous shifts in the active set of spinal interneurons during changes in locomotor speed. Nature 11, 1419-1429. doi: 10.1038/nn.2225

Meer, D. P., and Buchanan, J. T. (1992). Apamin reduces the late afterhyperpolarization of lamprey spinal neurons, with little effect on fictive swimming. Neurosci. Lett. 143, 1-4. doi: 10.1016/0304-3940(92)90219-w

Menelaou, E., and McLean, D. L. (2012). A gradient in endogenous rhythmicity and oscillatory drive matches recruitment order in an axial motor pool. J. Neurosci. 32, 10925-10939. doi: 10.1523/JNEUROSCI.1809-12.2012

Migliore, M., and Shepherd, G. M. (2002). Emerging rules for the distributions of active dendritic conductances. Nat. Rev. Neurosci. 3, 362-370. doi: 10. 1038/nrn810

Mills, L. R., Niesen, C. E., So, A. P., Carlen, P. L., Spigelman, I., and Jones, O. T. (1994). N-type Ca2+ channels are located on somata, dendrites and a subpopulation of dendritic spines on live hippocampal pyramidal neurons. $J$. Neurosci. 14, 6815-6824.

Müller, D. J., Helenius, J., Alsteens, D., and Dufrêne, Y. F. (2009). Force probing surfaces of living cells to molecular resolution. Nat. Chem. Biol. 5, 383-390. doi: $10.1038 /$ nchembio. 181

Muto, A., Ohkura, M., Kotani, T., Higashijima, S.-I., Nakai, J., and Kawakami, K. (2011). Genetic visualization with an improved GCaMP calcium indicator reveals spatiotemporal activation of the spinal motor neurons in zebrafish. Proc. Natl. Acad. Sci. U S A 108, 5425-5430. doi: 10.1073/pnas.10008 87108

Nakamura, K., and Yokotani, K. (2010). Presynaptic BK type Ca2+-activated $\mathrm{K}+$ channels are involved in prostanoid TP receptor-mediated inhibition of 
noradrenaline release from the rat gastric sympathetic nerves. Eur. J. Pharmacol. 629, 111-117. doi: 10.1016/j.ejphar.2009.11.056

Nanou, E., Alpert, M. H., Alford, S., and El Manira, A. (2013). Differential regulation of synaptic transmission by pre- and postsynaptic SK channels in the spinal locomotor network. J. Neurophysiol. 109, 3051-3059. doi: 10.1152/jn. 00067.2013

Nevian, T., and Sakmann, B. (2004). Single spine Ca2+ signals evoked by coincident EPSPs and backpropagating action potentials in spiny stellate cells of layer 4 in the juvenile rat somatosensory barrel cortex. J. Neurosci. 24, 1689-1699. doi: 10. 1523/jneurosci.3332-03.2004

Ngo-Anh, T. J., Bloodgood, B. L., Lin, M., Sabatini, B. L., Maylie, J., and Adelman, J. P. (2005). SK channels and NMDA receptors form a Ca2+-mediated feedback loop in dendritic spines. Nat. Neurosci. 8, 642-649. doi: 10.1038/nn1449

Nimchinsky, E. A., Sabatini, B. L., and Svoboda, K. (2002). Structure and function of dendritic spines. Annu. Rev. Physiol. 64, 313-353. doi: 10.1146/annurev. physiol.64.081501.160008

Noga, B. R., Kriellaars, D. J., Brownstone, R. M., and Jordan, L. M. (2003). Mechanism for activation of locomotor centers in the spinal cord by stimulation of the mesencephalic locomotor region. J. Neurophysiol. 90, 1464-1478. doi: 10. 1152/jn.00034.2003

Ohtsuki, G., Piochon, C., Adelman, J. P., and Hansel, C. (2012). SK2 channel modulation contributes to compartment-specific dendritic plasticity in cerebellar purkinje cells. Neuron 75, 108-120. doi: 10.1016/j.neuron.2012.05.025

Okado, N., Homma, S., Ishihara, R., and Kohno, K. (1990). Distribution patterns of dendrites in motor neuron pools of lumbosacral spinal cord of the chicken. Anat. Embryol. (Berl) 182, 113-121. doi: 10.1007/bf00174012

Patneau, D. K., and Mayer, M. L. (1990). Structure-activity relationships for amino acid transmitter candidates acting at N-methyl-D-aspartate and quisqualate receptors. J. Neurosci. 10, 2385-2399.

Placantonakis, D. G., and Welsh, J. P. (2001). Two distinct oscillatory states determined by the NMDA receptor in rat inferior olive. J. Physiol. 534, 123-140. doi: 10.1111/j.1469-7793.2001.t01-1-00123.x

Plotkin, J. L., Shen, W., Rafalovich, I., Sebel, L. E., Day, M., Chan, C. S., et al. (2013). Regulation of dendritic calcium release in striatal spiny projection neurons. J. Neurophysiol. 110, 2325-2336. doi: 10.1152/jn.00422.2013

Poirazi, P., Brannon, T., and Mel, B. W. (2003). Pyramidal neuron as two-layer neural network. Neuron 37, 989-999. doi: 10.1016/s0896-6273(03)00149-1

Poirazi, P., and Mel, B. W. (2001). Impact of active dendrites and structural plasticity on the memory capacity of neural tissue. Neuron 29, 779-796. doi: 10. 1016/s0896-6273(01)00252-5

Polsky, A., Mel, B. W., and Schiller, J. (2004). Computational subunits in thin dendrites of pyramidal cells. Nat. Neurosci. 7, 621-627. doi: 10.1038/nn1253

Pouille, F., and Scanziani, M. (2004). Routing of spike series by dynamic circuits in the hippocampus. Nature 429, 717-723. doi: 10.1038/nature02615

Riffell, J. A., Lei, H., and Hildebrand, J. G. (2009). Neural correlates of behavior in the moth Manduca sexta in response to complex odors. Proc. Natl. Acad. Sci. U S A 106, 19219-19226. doi: 10.1073/pnas.0910592106

Roberts, W. M. (1993). Spatial calcium buffering in saccular hair cells. Curr. Opin. Neurobiol. 363, 74-76. doi: 10.1038/363074a0

Roberts, A., and Alford, S. T. (1986). Descending projections and excitation during fictive swimming in Xenopus embryos: neuroanatomy and lesion experiments. J. Comp. Neurol. 250, 253-261. doi: 10.1002/cne.902500212

Roberts, A., Conte, D., Hull, M., Merrison-Hort, R., al Azad, A. K., Buhl, E., et al. (2014). Can simple rules control development of a pioneer vertebrate neuronal network generating behavior? J. Neurosci. 34, 608-621. doi: 10. 1523/JNEUROSCI.3248-13.2014

Roberts, A., Kahn, J. A., Soffe, S. R., and Clarke, J. D. (1981). Neural control of swimming in a vertebrate. Science 213, 1032-1034. doi: 10.1126/science.7196599

Rossignol, S., Bouyer, L., Barthélemy, D., Langlet, C., and Leblond, H. (2002). Recovery of locomotion in the cat following spinal cord lesions. Brain Res. Brain Res. Rev. 40, 257-266. doi: 10.1016/s0165-0173(02)00208-4

Rossignol, S., Chau, C., Brustein, E., Giroux, N., Bouyer, L., Barbeau, H., et al. (1998). Pharmacological activation and modulation of the central pattern generator for locomotion in the cat. Ann. N Y Acad. Sci. 860, 346-359. doi: 10. 1111/j.1749-6632.1998.tb09061.x

Rovainen, C. M. (1974). Synaptic interactions of identified nerve cells in the spinal cord of the sea lamprey. J. Comp. Neurol. 154, 189-206. doi: 10.1002/cne. 901540206
Rybak, I. A., Shevtsova, N. A., Lafreniere-Roula, M., and McCrea, D. A. (2006). Modelling spinal circuitry involved in locomotor pattern generation: insights from deletions during fictive locomotion. J. Physiol. 577, 617-639. doi: 10. 1113/jphysiol.2006.118703

Sah, P., and Bekkers, J. M. (1996). Apical dendritic location of slow afterhyperpolarization current in hippocampal pyramidal neurons: implications for the integration of long-term potentiation. J. Neurosci. 16, 4537-4542.

Sailer, C. A., Kaufmann, W. A., Marksteiner, J., and Knaus, H.-G. (2004). Comparative immunohistochemical distribution of three small-conductance $\mathrm{Ca} 2+-$ activated potassium channel subunits, SK1, SK2 and SK3 in mouse brain. Mol. Cell. Neurosci. 26, 458-469. doi: 10.1016/j.mcn.2004.03.002

Schiller, J., and Schiller, Y. (2001). NMDA receptor-mediated dendritic spikes and coincident signal amplification. Curr. Opin. Neurobiol. 11, 343-348. doi: 10. 1016/s0959-4388(00)00217-8

Schiller, J., Schiller, Y., Stuart, G., and Sakmann, B. (1997). Calcium action potentials restricted to distal apical dendrites of rat neocortical pyramidal neurons. J. Physiol. 505(Pt. 3), 605-616. doi: 10.1111/j.1469-7793.1997. 605ba.x

Schotland, J., and Grillner, S. (1993). Effects of serotonin on fictive locomotion coordinated by a neural network deprived of NMDA receptor-mediated cellular properties. Exp. Brain Res. 93, 391-398. doi: 10.1007/bf00229355

Schotland, J. L., Shupliakov, O., Grillner, S., and Brodin, L. (1996). Synaptic and nonsynaptic monoaminergic neuron systems in the lamprey spinal cord. J. Comp. Neurol. 372, 229-244. doi: 10.1002/(sici)10969861(19960819)372:2<229::aid-cne6>3.3.co;2-j

Schotland, J., Shupliakov, O., Wikström, M., Brodin, L., Srinivasan, M., You, Z. B., et al. (1995). Control of lamprey locomotor neurons by colocalized monoamine transmitters. Nature 374, 266-268. doi: 10.1038/374266a0

Schwartz, E. J., Blackmer, T., Gerachshenko, T., and Alford, S. (2007). Presynaptic G-protein-coupled receptors regulate synaptic cleft glutamate via transient vesicle fusion. J. Neurosci. 27, 5857-5868. doi: 10.1523/jneurosci.1160-07. 2007

Schwartz, E. J., Gerachshenko, T., and Alford, S. (2005). 5-HT prolongs ventral root bursting via presynaptic inhibition of synaptic activity during fictive locomotion in lamprey. J. Neurophysiol. 93, 980-988. doi: 10.1152/jn.00669.2004

Shah, M. M., and Haylett, D. G. (2002). K+ currents generated by NMDA receptor activation in rat hippocampal pyramidal neurons. J. Neurophysiol. 87, 29832989.

Sholomenko, G. N., and Steeves, J. D. (1987). Effects of selective spinal cord lesions on hind limb locomotion in birds. Exp. Neurol. 95, 403-418. doi: 10.1016/00144886(87)90148-8

Sigvardt, K. A., Grillner, S., Wallén, P., and Van Dongen, P. A. (1985). Activation of NMDA receptors elicits fictive locomotion and bistable membrane properties in the lamprey spinal cord. Brain Res. 336, 390-395. doi: 10.1016/00068993(85)90676-6

Sirota, M. G., Di Prisco, G. V., and Dubuc, R. (2000). Stimulation of the mesencephalic locomotor region elicits controlled swimming in semi-intact lampreys. Eur. J. Neurosci. 12, 4081-4092. doi: 10.1046/j.1460-9568.2000.00301.x

Smith, J. J., Kuraku, S., Holt, C., Sauka-Spengler, T., Jiang, N., Campbell, M. S., et al. (2013a). Sequencing of the sea lamprey (Petromyzon marinus) genome provides insights into vertebrate evolution. Nat. Genet. 45, 415-421, 421e1421e2. doi: $10.1038 /$ ng. 2568

Smith, S. L., Smith, I. T., Branco, T., and Häusser, M. (2013b). Dendritic spikes enhance stimulus selectivity in cortical neurons in vivo. Nature 503, 115-120. doi: 10.1038 /nature12600

Spruston, N. (2008). Pyramidal neurons: dendritic structure and synaptic integration. Nat. Rev. Neurosci. 9, 206-221. doi: 10.1038/nrn2286

Stackman, R. W., Hammond, R. S., Linardatos, E., Gerlach, A., Maylie, J., Adelman, J. P., et al. (2002). Small conductance $\mathrm{Ca} 2+$-activated $\mathrm{K}+$ channels modulate synaptic plasticity and memory encoding. J. Neurosci. 22, 10163-10171.

Stuart, G. J., and Häusser, M. (2001). Dendritic coincidence detection of EPSPs and action potentials. Nat. Neurosci. 4, 63-71. doi: 10.1038/82910

Stuart, G., Spruston, N., Sakmann, B., and Häusser, M. (1997). Action potential initiation and backpropagation in neurons of the mammalian CNS. Trends Neurosci. 20, 125-131. doi: 10.1016/s0166-2236(96)10075-8

Svensson, E., Grillner, S., and Parker, D. (2001). Gating and braking of short- and long-term modulatory effects by interactions between colocalized neuromodulators. J. Neurosci. 21, 5984-5992. 
Svoboda, K., Denk, W., Kleinfeld, D., and Tank, D. W. (1997). In vivo dendritic calcium dynamics in neocortical pyramidal neurons. Nature 385, 161-165. doi: $10.1038 / 385161 \mathrm{a} 0$

Svoboda, K., Tank, D. W., and Denk, W. (1996). Direct measurement of coupling between dendritic spines and shafts. Science 272, 716-719. doi: 10.1126/science. 272.5262.716

Takahashi, N., Kitamura, K., Matsuo, N., Mayford, M., Kano, M., Matsuki, N., et al. (2012). Locally synchronized synaptic inputs. Science 335, 353-356. doi: 10. 1126/science. 1210362

Takahashi, H., and Magee, J. C. (2009). Pathway interactions and synaptic plasticity in the dendritic tuft regions of CA1 pyramidal neurons. Neuron 62, 102-111. doi: 10.1016/j.neuron.2009.03.007

Topolnik, L., Chamberland, S., Pelletier, J.-G., Ran, I., and Lacaille, J.-C. (2009). Activity-dependent compartmentalized regulation of dendritic $\mathrm{Ca} 2+$ signaling in hippocampal interneurons. J. Neurosci. 29, 4658-4663. doi: 10. 1523/jneurosci.0493-09.2009

Vaidya, S. P., and Johnston, D. (2013). Temporal synchrony and gamma-to-theta power conversion in the dendrites of CA1 pyramidal neurons. Nat. Neurosci. 16, 1812-1820. doi: 10.1038/nn.3562

Viana di Prisco, G., and Alford, S. (2004). Quantitative investigation of calcium signals for locomotor pattern generation in the lamprey spinal cord. J. Neurophysiol. 92, 1796-1806. doi: 10.1152/jn.00138.2004

Vonhoff, F., and Duch, C. (2010). Tiling among stereotyped dendritic branches in an identified Drosophila motoneuron. J. Comp. Neurol. 518, 2169-2185. doi: 10. $1002 /$ cne. 22380

Vrieseling, E., and Arber, S. (2006). Target-induced transcriptional control of dendritic patterning and connectivity in motor neurons by the ETS gene Pea3. Cell 127, 1439-1452. doi: 10.1016/j.cell.2006.10.042

Wall, M. J., and Dale, N. (1995). A slowly activating Ca(2+)-dependent K+ current that plays a role in termination of swimming in Xenopus embryos. J. Physiol. 487(Pt. 3), 557-572.

Wallén, P., Buchanan, J. T., Grillner, S., Hill, R. H., Christenson, J., and Hökfelt, T. (1989). Effects of 5-hydroxytryptamine on the afterhyperpolarization, spike frequency regulation and oscillatory membrane properties in lamprey spinal cord neurons. J. Neurophysiol. 61, 759-768.

Wallén, P., Ekeberg, O., Lansner, A., Brodin, L., Tråvén, H., and Grillner, S. (1992). A computer-based model for realistic simulations of neural networks. II. The segmental network generating locomotor rhythmicity in the lamprey. J. Neurophysiol. 68, 1939-1950.

Wallén, P., and Grillner, S. (1987). N-methyl-D-aspartate receptor-induced, inherent oscillatory activity in neurons active during fictive locomotion in the lamprey. J. Neurosci. 7, 2745-2755.

Wallén, P., and Williams, T. L. (1984). Fictive locomotion in the lamprey spinal cord in vitro compared with swimming in the intact and spinal animal. J. Physiol. 347, 225-239.

Wang, X. J. (2001). Synaptic reverberation underlying mnemonic persistent activity. Trends Neurosci. 24, 455-463. doi: 10.1016/s0166-2236(00) 01868-3

Wang, X.-J. (2010). Neurophysiological and computational principles of cortical rhythms in cognition. Physiol. Rev. 90, 1195-1268. doi: 10.1152/physrev.00035. 2008

Wang, D., Grillner, S., and Wallén, P. (2013). Calcium dynamics during NMDA-induced membrane potential oscillations in lamprey spinal neuronscontribution of L-type calcium channels (CaV1.3). J. Physiol. 591, 2509-2521. doi: 10.1113/jphysiol.2012.248526

Wang, D., Grillner, S., and Wallén, P. (2014a). Endogenous release of 5-HT modulates the plateau phase of NMDA-induced membrane potential oscillations in lamprey spinal neurons. J. Neurophysiol. 112, 30-38. doi: 10.1152/jn.00582. 2013

Wang, K., Lin, M. T., Adelman, J. P., and Maylie, J. (2014b). Distinct Ca2+ sources in dendritic spines of hippocampal CA1 neurons couple to SK and Kv4 channels. Neuron 81, 379-387. doi: 10.1016/j.neuron.2013.11.004

Wehr, M., and Laurent, G. (1996). Odour encoding by temporal sequences of firing in oscillating neural assemblies. Nature 384, 162-166. doi: 10.1038/384162a0

Wei, A. D., Gutman, G. A., Aldrich, R., Chandy, K. G., Grissmer, S., and Wulff, H. (2005). International Union of pharmacology. LII. Nomenclature and molecular relationships of calcium-activated potassium channels. Pharmacol. Rev. 57, 463472. doi: $10.1124 /$ pr.57.4.9
Wei, D. S., Mei, Y. A., Bagal, A., Kao, J. P., Thompson, S. M., and Tang, C. M. (2001). Compartmentalized and binary behavior of terminal dendrites in hippocampal pyramidal neurons. Science 293, 2272-2275. doi: 10.1126/science.10 61198

Weiler, N., Wood, L., Yu, J., Solla, S. A., and Shepherd, G. M. G. (2008). Top-down laminar organization of the excitatory network in motor cortex. Nat. Neurosci. 11, 360-366. doi: 10.1038/nn2049

Westenbroek, R. E., Ahlijanian, M. K., and Catterall, W. A. (1990). Clustering of L-type Ca2 + channels at the base of major dendrites in hippocampal pyramidal neurons. Nature 347, 281-284. doi: 10.1038/347281a0

Westenbroek, R. E., Hell, J. W., Warner, C., Dubel, S. J., Snutch, T. P., and Catterall, W. A. (1992). Biochemical properties and subcellular distribution of an Ntype calcium channel alpha 1 subunit. Neuron 9, 1099-1115. doi: 10.1016/08966273(92)90069-p

Wikström, M., Hill, R., Hellgren, J., and Grillner, S. (1995). The action of 5-HT on calcium-dependent potassium channels and on the spinal locomotor network in lamprey is mediated by 5-HT1A-like receptors. Brain Res. 678, 191-199. doi: 10. 1016/0006-8993(95)00183-q

Wikström, M. A., and El Manira, A. (1998). Calcium influx through Nand $\mathrm{P} / \mathrm{Q}$-type channels activate apamin-sensitive calcium-dependent potassium channels generating the late afterhyperpolarization in lamprey spinal neurons. Eur. J. Neurosci. 10, 1528-1532. doi: 10.1046/j.1460-9568.1998. 00194.x

Williams, T. L. (1992). Phase coupling by synaptic spread in chains of coupled neuronal oscillators. Science 258, 662-665. doi: 10.1126/science. 1411575

Williams, S. R., and Stuart, G. J. (2003). Role of dendritic synapse location in the control of action potential output. Trends Neurosci. 26, 147-154. doi: 10. 1016/s0166-2236(03)00035-3

Womelsdorf, T., Valiante, T. A., Sahin, N. T., Miller, K. J., and Tiesinga, P. (2014). Dynamic circuit motifs underlying rhythmic gain control, gating and integration. Nat. Neurosci. 17, 1031-1039. doi: 10.1038/nn.3764

Xu, N.-L., Harnett, M. T., Williams, S. R., Huber, D., O'Connor, D. H., Svoboda, K., et al. (2012). Nonlinear dendritic integration of sensory and motor input during an active sensing task. Nature 492, 247-251. doi: 10.1038/nature 11601

Yamada, S.-I., Takechi, H., Kanchiku, I., Kita, T., and Kato, N. (2004). Smallconductance $\mathrm{Ca} 2+$-dependent $\mathrm{K}+$ channels are the target of spike-induced $\mathrm{Ca} 2+$ release in a feedback regulation of pyramidal cell excitability. J. Neurophysiol. 91, 2322-2329. doi: 10.1152/jn.01049.2003

Yuste, R., and Denk, W. (1995). Dendritic spines as basic functional units of neuronal integration. Nature 375, 682-684. doi: 10.1038/375682a0

Yuste, R., MacLean, J. N., Smith, J., and Lansner, A. (2005). The cortex as a central pattern generator. Nat. Rev. Neurosci. 6, 477-483. doi: 10.1038/ nrn 1686

Zhang, W., and Grillner, S. (2000). The spinal 5-HT system contributes to the generation of fictive locomotion in lamprey. Brain Res. 879, 188-192. doi: 10. 1016/s0006-8993(00)02747-5

Zhang, W., Pombal, M. A., El Manira, A., and Grillner, S. (1996). Rostrocaudal distribution of 5-HT innervation in the lamprey spinal cord and differential effects of 5-HT on fictive locomotion. J. Comp. Neurol. 374, 278-290. doi: 10. 1002/(sici)1096-9861(19961014)374:2<278::aid-cne9>3.0.co;2-\#

Conflict of Interest Statement: The authors declare that the research was conducted in the absence of any commercial or financial relationships that could be construed as a potential conflict of interest.

Received: 30 June 2014; accepted: 31 August 2014; published online: 18 September 2014.

Citation: Alford ST and Alpert MH (2014) A synaptic mechanism for network synchrony. Front. Cell. Neurosci. 8:290. doi: 10.3389/fncel.2014.00290 This article was submitted to the journal Frontiers in Cellular Neuroscience.

Copyright (C) 2014 Alford and Alpert. This is an open-access article distributed under the terms of the Creative Commons Attribution License (CC BY). The use, distribution or reproduction in other forums is permitted, provided the original author (s) or licensor are credited and that the original publication in this journal is cited, in accordance with accepted academic practice. No use, distribution or reproduction is permitted which does not comply with these terms. 